Pz-D 1901

DIESELDORFF, A.

BEITRAGE ZUR KENNTMISS DER GESTEINE UND FOSSILIEN DER CHATHAMINSELN SOWIE EINIGER GESTEINE UND NEUER NEPHRITFUNDORTE NEU-SEELANDS. 


\section{$\checkmark$}




\title{
Beiträge zur Kenntniss
}

\section{der Gesteine und Fossilier der Chathaminseln} sowie einiger Gestein wa neuer Nephritfundorte Neu-Seelands.

\section{Inaugural-Dissertation \\ zur}

\author{
Erlangung der Doktorwürde
}

der

Ilohen Plilosopliselıen Pakultät der Universität Marhurg

vorgelegt von

Arthur Dieseldorff

aus Hamburg

M a r burg.

Universitäts-Buchdruckerei (R. Friedrich).

${ }^{S m} 1901$. 


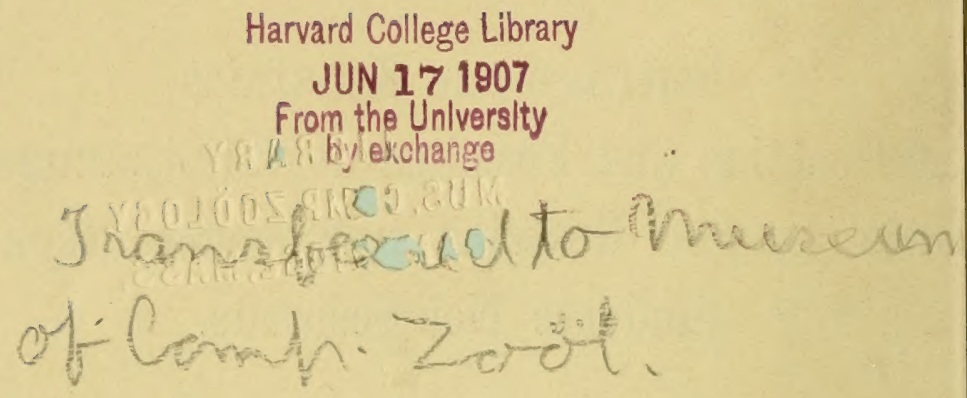

Von der philosophischen Fakultät als Dissertation angenommen am 26. Juni 1901. 
Seinem ersten Lehreer in G'eologie und Petrograplie

\title{
Herrn Prof. Dr. Richard Reck in Freiberg in Sachsen
}

\author{
aus Dankbarkeit und ans Ehrerbietung gewidmet.
}



Im Jahre 1896-1897 besuchte der Director des Bremer Musenms für Natur-, Völker- und Handelskunde, Herr Prof. Dr. H. Schauinsland, auf einer zoologischen Forschungsreise die Chatham-Inseln (siehe Tafel I) und denjenigen Teil der Südinsel Neu-Seelands, welcher an die Cook-Strasse grenzt und der die D'Urville- und die Stephens-Insel sowie einige umliegende Meeresbuchten und kleinere Inselgruppen umfasst (siehe Tafel III). Seine petrographische Ausbeute und die wenigen von ihm gesammelten Fossilien übersandte er zur Bearbeitung dem Marburger mineralogischen Institut, dessen Director, Herr Geh. Reg. - Rath Prof. Dr. Max Bauer, sie mir zur Untersuchung übergab.

Diese mir übertragene Arbeit teile ich ein in:

A) Die Gesteine der Chatham-Inseln . . . 6

B) Die Gesteine der D'Urville- und der StephensInsel, der Trio- und der Rangitoto-Inselgruppe sowie der Elmsley-Bay, sämmtlich an der Cook-Strasse gelegen . . . . . . . . 30

C) Die Nephrite der D'Urville und der StephensInsel, darunter Nephrit im Muttergestein von der D'Urville-Insel. . . . . . . 42

I) Die Fossilien der unter A) und B) genannten Inseln und Inselgruppen . . . . . . . . . . . . . 55

Die Originale zu den auf Tafel I, II und III wiedergegebenen Karten und Ansichten habe ich aus dem Bestande des Bremer M u se u m s erhalten. 


\section{A.}

\section{Die Gesteine der Chatham-Inseln.}

Als Literatur kommt für diese Inselgruppe in Betracht:

1. Ernst Dieffenbach, An Account of the Chatham Islands (Journal Royal Geographical Soc. London 1841. XI. S. 195/215).

2. Julius v. Hast, Notes on Rock Specimens collected by H. H. Travers on the Chatham Islands (Transactions New Zealand Inst. Wellington 1868. I oder deren erster Nachdruck 1875 S. 127/129).

3. James Hectior, Notes on the Geology of the Outlying Islands (ibidem 1870. II. S. 176/186).

4. James Hector, gleicher Titel (ibidem 1896. XXVIII S. 737/738).

5. Carl E. Meinecke, Die Inseln des stillen Oceans. Leipzig 1875. I.

6. Georg H. F. Ulrich, On the Occurence of Nepheline bearing rocks in New Zealand (Report 3rd meeting, Austral. Ass. for the Advancement of Science. Sydney 1891. S. 127 150).

7. F. W. Hutton, On the foliated rocks of Otago (Transactions New Zealand Inst. Wellington 1891. XXIV. S. 35965).

8. Derselbe, The geological history of New Zealand (ibidem 1899. XXXII. S. 159 seq.).

9. Bruno Weiss, 50 Jahre auf den Chatham-Inseln. Berlin 1901.

Bei Citirung der obigen Quellen im Text gebrauche ich die Bezeichnung: (Lit. Nr. ...).

Die Chatham-Inseln bestehen aus der Hauptinsel Wharekauri, dem kleineren Pitt-Island und einigen Felseneilanden. Die Gesteine des Inselkomplexes bieten nur geringfügige Unterschiede, so dass sie gemeinsam besprochen werden sollen. In der folgenden 58 Gesteinsnummern umfassenden Übersicht und im folgenden Text zeigt ein vorgesetztes "P“ an, dass das betreffende Gestein von dem Flowerpot-Hafen auf Pitt-Island stammt, während alle übrigen auf der Hauptinsel gesammelt wurden.

Ausserdem hat Schauinsland noch 82 den Ureinwohnern der Chatham-Inseln, den Morioris und Maoris, ab- 
gekaufte Stein-Artefakte mitgebracht. Unter diesen finden sich Sericitschiefer, Feldspat- und Nephelinbasalte, Magmabasalte und Trachyte, welche jedoch an anderer Stelle abgehandelt werden sollen.

Übersicht und Einteilung (nach Rosenbusch's Gesteinslehre).

I. Krystalline Schiefer.

Sericitschiefer: Nr. 1. 2. 3. 5. 6. 7. - Letzterer führt Graphitoid und Zoisit.

Andesit: P 6 a.

II. Eruptiv-Gesteine.

Feldspatbasalte: Nr. 17. 19. 27b. 37-39. 43.

Magmabasalte: Nr. $32-34$.

Palagonittuffe und Tuffoide: Nr. 18. 20. 28-30. 35. 42; P 1 und 3.

III. Schichtige Gesteine.

Kieseltuff: Nr. 41; Sandsteine: Nr. 4 und $40 \mathrm{~b}$; Thone: Nr. 15 und 16. Kalksteine: Nr. 8-14. 21. 22. 26. 31; P 4. 5. 7 und 8.

Kalksteine mit Basaltgeröllen: Nr. 23a. 25. 36.

Eisensteine: Nr. 23 b. 24. 27a; P 2.

Meeressand: Nr. 49 und 50.

Magnesit: Nr. P 6 b.

IV. Mineralien.

Schwefelkies: Nr. 44 und 48.

Opal, Eisenkiesel, Hornsteine, Jaspis und Feuersteine: Nr. 40a. 45 a b c. 46. $47 \mathrm{a}$ und $\mathrm{b}$.

Bevor ich nun meiner eigentlichen Aufgabe, nämlich der petrographischen Beschreibung, mich widme, möge eine kurze Skizzierung dieser entlegenen, aber geologisch interessanten Inselgruppe voraufgehen. Das Tagebuch und die Sammlungen Schauinsland's bereichern wesentlich unsere Kenntnisse über diese Inseln, die bisher in der Hauptsache von den unter Lit. Nr. 1 2 und 3 genannten Autoren beschrieben worden sind.

Bereits D i effe $\mathrm{nbach}$ (Lit. Nr. 1) unterscheidet: Glimmerschiefer, Basalte und Kalksteine und bemerkt, dass die Tektonik der Inseln mit derjenigen der Südinsel Neu-Seeland's identisch sei. v. H a ast (Lit. Nr. 2) beschreibt etwas eingehender die Gesteine, bestimmt einige Fossilien als alttertiär und zieht Vergleiche zwischen dem Aufbau der Inselgruppe und dem ge- 
nannten Teil Neu-Seelands, dem "middle island" der englischen Autoren. Hector (Lit. $\mathrm{Nr}$. 3) gliedert unteres und oberes Tertiär, und giebt an, dass die Eruptiv-Gesteine der letzteren Formation angehören. Er hebt hervor, dass die recente Moorund Torfbildung nicht mit den alttertiären Braunkohlen-Ablagerungen verwechselt werden dürfe. Seiner Ansicht nach bilden die Chatham-Inseln in geologischer Hinsicht einen Teil der $900 \mathrm{~km}$ westlich gelegenen südinsel Nen-Seelands, zumal das Meer zwischen beiden, wie durch Lotungen festgestellt sei (Lit. Nr. 4), nicht über $600 \mathrm{~m}$ tief ist.

Zieht man von der Waitangi-Bucht nach dem Südende der Lagune eine Linie, so teilt diese zugleich die Hauptinsel in zwei geologisch verschiedene Hälften. Die südliche besteht, wie die Pitt-Insel, ausschliesslich aus jüngeren Eruptiv-Gesteinen und deren Tuffen, während der nördliche Teil in seinen tieferen Niveaus von palaeozoischen Sericitschiefern gebildet wird, die von den jüngeren vulkanischen Gesteinen überlagert und durchbrochen werden.

Die Sericitschiefer trifft man anstehend am Strande des Westkaps bei Te Raki, am Ostkap bei Te Wakuru, bei Rangikapua und dessen südlicher Umgebung, dann an verschiedenen Punkten des Nordufers, so am Mt. Engst (Maunganui der Eingeborenen) und am Cape Pattison. Das nordwestliche Gestade der Lagune, ungefähr gegenüber dem Mt. Korako, und die Umgebung des Hutt-Hafen (Whangaroa der Eingeborenen) sind die südlichsten Punkte, wo sie als anstehendes Gestein auftreten. Hier sind sie im Gegensatz zu den Fundorten am Nordufer, wo ihnen ein nordwestliches Verflachen eigen ist, steil aufgerichtet und fallen unter einem Winkel von $30^{\circ}-50^{\circ}$ südlich ein, während ihre Streichrichtung allerwärts SW nach NO ist. Sie werden überall nur im tiefsten Niveau der Insel, am Ufer, angetroffen, wie Abbildung 1 auf Tafel II zeigt. Hector bemerkt, dass sie den silurischen grünen, gefalteten und goldführenden Glimmerschiefern der Provinz Otago auf Neu-Seeland völlig gleichen, die Hutton (Lit. Nr. 7) nach seiner Untersuchung als praecambrisch ansieht. v. Ha ast identificirt sie mit den Glimmerschiefern des Mt. Cook und der Moorhouse Range auf Neu-See- 
land. Die sericitschiefer dienen den Bassilt- mol Tullikegehn des

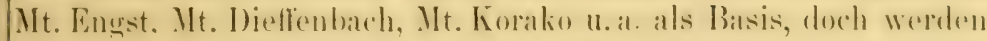
sie auch ron Basaltgängen, wie z. B. am letztgenannten Orte, durchbrochen. Als Strandgeschiebe liegen sie von Te One in der Waitangi-Bucht vor.

Die Eruptivgesteine und deren T' $\mathrm{T}$ ffe nehmen den grössten Teil der Inseln ein und ron ilmen hesonders hornblende-

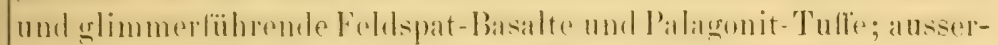
dem kommen noch Andesite und Magmabasalte vor. Trachyte sowie Tephelin-Basalte hefinden sich unter den Artelakten. Die Tuffe werden von Basaltgïngen durchsetzt, so an den Red hluffs und am Point (latchi; ferner sind ihnen schalalige Eisensteine eingelagert, auch enthalten sie Knollen von ('al cit, II a nesit, Opal und Chalcedon. Ausgedehnte Kieseltuff-Bildungen trifit man anf dem Wege zwischen Te One und dem Hutt-llafen und am Strande zwischen den heiden Oiten kommen helle und dunkle Bimssteine, Feuersteine und gelber $\mathrm{J}$ asp is vor.

$\mathrm{Kalksteine} \mathrm{sind} \mathrm{auf} \mathrm{den} \mathrm{Chatham-Inseln} \mathrm{sehr} \mathrm{verbreitet,}$ hesonders zwischen Waitangi und dem südlichen Teil der Latgune. v. II a as t (lit. Nr. 2) hält die ihm ühersandten Kalksteine für verschiedenaltrig; seine Beobachtung ist richtig gewesen. Er meint, sie seien teilweise paläozoischen Alters. Nach Schauinslands Mitteilungen ist ihr geologisches Auftreten auf den ('hathamInseln von dreierlei verschiedener Art und Weise:

a) Am Südende der Lagune, dann auf der teils aus Kalkstein teils aus glimmerführendem Basalte ( Nr. 1!) hestehenden Insel Rangatira in der Lagune, und am und im Lake Huro ragen bis zu zwanzig und mehr Meter hohe zerrissene Klippen eine's dichten, festen krystallinischen Kalksteins (Nr. 10-12) von weisser, gelblicher und rosa Farbe empor, denen die Nr. P 5.7 und 8 gleichen. Sie sind mit den stacheh einer kretaceischen mit (idaris (Phyllacanthus?) rerticillata Lam. verwandten det sowie mit Bryozoen- und Schwammresten gerade\%u erfüllt und danach wohl alter als tertiar, aher keineswerg palituzoisch. r. I a ast's Angalie hezieht sich auf diese Kalksteine und kann nur ohne Kemntnis ihres fossilen Inhalts ahgegehen sein. Am Ifer der Lagune, etwas nördlich der Insel Rangatira, wird der mit den 
gleichen Seeigelstacheln erfüllte Kalkstein olt sehr weich, sollass sich die Morioris Höhlen darin graben konnten: in ihren Wänden findet sich noch heute eine eingeritzte Bilderschrift An den Red Bluffs trift man den durch den gleichen fossilen Inhalt charakterisirten Kalkstein wiederum an und zwar in bedeutender Mächtigkeit und in weicheren und härteren Partien.

b) Am Nordufer der llauptinsel finden sich bei Whakekauri und bei Tioreors weiche weisse Kalkbänke (Nr. 31) mit kleinen dünnschaligen, sehr jungen Gryphaeen und grossen in Limonit verwandelten, ebenfalls jungtertiären Pectiniclen (Beschreibung unter D).

c) Ein zum Teil aus Kalkalgen aufgebauter zerreiblicher Kalktuff (Nr. 8 und 9) kommt nach Schau inslands Mitteilungen mit den Tuffen und den Laven der beiden Inseln zusammen vor.

Wandernde I ün en, die wie an der kurischen Nehrung (iehölze verschütten, üher die sie hinwegwandern (siehe Tafel II, 1) und dabei an den Bäumen die bekannten Veränderungen hervorrufen, sind an der Nordküste der Hauptinsel und am Gestade des nördlichen T'eils der Lagune weit verbreitet (S c h a u i n s l a n d).

Braunkohlen finden sich auf dem westlichen Teil der nach Hector's Ansicht (Lit. Nr. 4) aus tertiären und kretaceischen Gesteinen aufgebauten Pitt-Insel; sie repräsentieren die im gleichen Niveau befindlichen brown coal series von NeuSeeland. Dieffenbach erwähnt die aus monocotyledonen P'llanzen gebildeten "lignite beds" im Hafen von Kaingaroa, unweit des Ostcaps. Ausgedehnte Moore findet man auf dem Wege vom Hutt-Haten nach der Waitangi-Bucht und ferner auf dem ganzen südlichen Teil der Hauptinsel, der deshalb einen rauhen unwirtlichen Eindruck macht und unbewohnt ist. Diese Torf- und Noorbildungen sind stellenweise in Brand geraten, und die dadurch eintretende Volumverminderung veranlasst zahlreiche Erdfaille.

Bestimmte Angaben über das Alter der Gesteine vermag ich, da nur wenige Fossilien vorliegen, die innerhalb der Kreide und des Tertïirs keinen engbegrenzten Horizont wiedergeben, und da Profile fehlen, nicht zu machen. 
Ausser der zwei Druckseiten langen Abhandlung v. Ilaast's (Lit. Nr. 2) über die Gesteine der Chatham-Inseln, welche er nur nach ihren äusserlichen Merkmalen hestimmt und heschreibt. ist keine weitere petrographische Arbeit über dieses 'Thema erschienen.

Bei der nummehr folgenden Beschreihung der Gesteine wirl die Nummerirung Schaninsland's beibehalten.

\section{Krystalline Schiefer.}

Die von den angeführten Punkten vorliegenden 6 Stufen sind mit Ausnahme der Nr.7 echte feinkrystallinische Sericitschief'er von grüner Farbe, die bei Verwitterung ins bräunliche ïhergeht. Sie sind oft gehogen und stark gefältelt, besitzen aber eine ausgezeichnete Parallelstruktur und sind dann in 2 bis $3 \mathrm{~cm}$ starke Platten abgesondert, welche als Treppen- und Fussbodenheläge an Ort und Stalle henutzt werden. Die Schiefer werden von Quarzgïngen (Nr.2 und 3) durchzogen, die sich bis zu (uarzlinsen ("fuartz hlows" der Englinder) differenziren können, wie sie z. B. bei Te Wakuru in äber mannshohen und aus dem (iesteinsverbande losgelösten Blïcken sich finden. Schmale Trümer, die mit einem Gemenge von sekundärem Quarz und Feldspat erfüllt sind, durchziehen die Schiefer in einer mehr oder minder zu den sichichtlächen, die zugleich Absonderungsfliachen sind, senlirechten Richtung. I) ynamische Torgänge hahen die Fälelung und steilstellung der sichiefer, damn die Augenstruktur der Stufe Nr. 7 von Te Raki hervorgerufen. Der miliroskopische Befund hestitigt im Kileinen die Wirkungen der Dynametamorphose. If utton gibt an (Lit. Nr. 7), dass die den Sericitschiefern der ('hatham-Inseln gleichenden "foljated rocks of Otago" altered eruptive rocks sind, bleibt aber einen objektiven Beweis für seine Annahme schuldig. Ich habe aus der mikroskopischen I'ntersuchung der oligen sechs Ilandstücke und der vielen aus demselhen Gestein gefertigten Artefalite keinen bestimmten Anhalt finden können, dass die sericitschiefer metitmorphisirte Eruptiv-Gesteine sind, wie es z. B. Schauf in den Berichten der senckenberg. (ies. für 189s lür diejenigen des 
Ta un us dargethan hat, denen die Schiefer der Chatham-Inseln in vieler Beziehung gleichen. Sie sind aher zweifellos metamorphisirte und keine primären (iesteine, wie die nun folgende mikroskopische Beschreibung darthut.

Die Sericitschiefer hestehen in der Hauptsache aus Quarz und (ilimmer, denen sich Feldspat und zwar gelegentlich in urösserer . Venge zugesellt. Dersellhe gewinnt aher nie eine solche Berleutung, um deshall, das fiestein als Sericitgneiss hezeichnen zu können. Graphitoid und Zoisit spielen in Nr. 7 die Rolle von wesentlichen Gemengteilen. Accessorisch treten hinzu: Zoisit in einer anderen Aushildung als in Nr. 7, Ifelminth und Viridit, Zirkon, Epidot, Aktinolit, Titanit, Granat, Calcit, Magnetit und Pyrit.

Der Quarz tritt in zwiefacher Modifikation auf: erstens als ein ursprünglicher Bestanlteil des primären Gesteins, aus dem die Sericitschiefer entstanden sind, also als älterer Quarz; und dann als jüngere und sekundirre Bildung. Als solche fiillt er mit Feldspat die schon makroskopisch erkennbaren und erwähnten Trümer aus.

Im ersteren Fall bildet er unregelmässige rundliche und eckige Körner, die durch ihre Grösse, ebenso wie die unten beschriehenen Feldspatkörner, sich ans der feinkörnigen Cresteins. masse dentlich abhehen. Die ()uare sind nicht selten gestreckt und sehen wie ausgewalat aus oder sie sind auch von einer rundlichen, aus Quarzfragmenten bestehenden Trümmerzone umgeben. Fast immer werden sie mit einer ihrer Form sich anpassenden peripheren Anordnung von Quarz und Feldspatsplitterchen und einigen Sericitschüpphen umgeben, sodass dadurch eine mehr oder minder deutliche centrische Struktur entsteht, deren Ker'n eben älter sein muss als die ihn umschliessenden Mineralien, also auch als der Sericit. Mehrere unter sich parallele oder auch sich durchkreuzende gradlinige selten gebogene Reihen von Einschlüssen durchziehen ihn; sie bestehen aus winzigen stabförmigen rotbraunen und schwarzen Nädelchen, deren Natur sich selbst mit den stärksten Systemen nicht feststellen liess. Flüssigkeitseinschlüsse wurden nicht beobachtet. J)iese Mikrolithen hören an der Grenze des Quarzkorns auf, 
äberspringen manchmal den feinen zwischen \%wei ()narzkörnern befindlichen diesteinsyrus und treten dinn im zweiten Individum - unter Beibehaltung der ursprünglichen lichtung wieder auf. Nur der primäre, nicht der sekmulire Quar\% enthält diese Einschlüsse und ihr Vorhandensein gibt uns ein Mittel an die Hand, den (2nar\% ron den ihm sonst gleichenden einfachen Feldspatindividuen zu unterscheiden, zumal die Anwendung des converg. polar. Lichtes nicht immer und sicher zum Ziel führt. ()lters wurden (quarze beobachtet, die im gewöhnlichen Liclst von mehreren Reihen von Einschlüssen durchzogene homogene Individuen ohne erkembare Spaltrisse darstellen, die jedoch unter gekreuzten Nicols in viele nach verschiedener Richtung und undulös auslöschende Teile zerfallen, ohne dass die ursprüngliche und gradlinige Richtung der Einschlüsse sich dabei verïndert hätte. Diese Erscheinung dürlte anf Druck und kataklastische Vorgänge im (iestein zurückzuführen sein. Ausser den ohen beschriebenen Einschlüssen treten im Quarz noch Nidelchen eines hellgrünen Aktinolits auf, der oft von einer schwärzlichen Sulsstan\% mehr oder minder erlïllt ist. Der sekundäre Quarz füllt mit Feldspat als Mosaik die nachträglichen Gesteinsklüfte aus, ist einschlussfrei und hietet nichts Erwähnenswertes.

Auch der Feldspat ist in zweierlei Form vorhanden. Er wird erstens ähnlich wie der primäre Quarz peripherisch von einem aus (quarz-, Feldspat- und Sericitteilchen, Aktinulitprismen, Zoisitkryställchen und Epidothörnchen hestehenden Mantel, welcher centrische struktur besitzt, umgeben. Der Feldspat ist sowohl völlig frisch und klar als auch durch beginnende Zersetzung getrübt; in letaterem laall tritt die polysynthetische Lamellirung des Plagioklas deutlicher hervor. Sericitschuppen durchziehen den Feldspat in regelloser Weise oder siedeln sich auf den Bliitterbrüchen an. Bemerkenswert sind Sericit-Anhäufungen inmitten der an weitesten zersetzten Plagioklase, die ans einem Sericitkern und einer Feldspatrinde hestehen, sodass hier eine Verwitterung von inmen nach aussen vorliegt, die so weit gehen kann, dass die feldspatsubstanz gänzlich verschwindet und an ilıre stelle sericit tritt. Die alteren lieldspite weisen ehenlalls kataklastische Merkmale auf, sie löschen ohne Ausnahme un- 
dulös aus. sind zerhrochen und die einzelnen Stücke aus ihree Jüngserstreckung verriickt, zngleich sind die Zwillingslamellen mit verworten warden. Als zweiter und jüngerer. Feldspat füllt er mit ()uarz die (iesteinsklüfte aus und zwar sowohl in lamellirten wie in nicht lamellirten Körnern, die aber stets einheitliche Auslöschung besit\%en.

Als G limmer kommt nur der Sericit mit den bekannten Eigenschaften vor, ausser im Gestein Nr.7, wo neben ihm in dem graphitoid- und zoisitliuhrenden Sericitschiefer noch reichlicher Uuscovit aultritt, der meist zu Linsen vereinigt ist: doch auch in büschligen und strahligen Aggregaten sich tindet. Zum Teil ist der im reflectirten Licht seidenglïnzende Muscovit aus Zoisit entstanden, wie wir gleich sehen werden.

Zo isit findet sich zwielach ausgebildet. In den Schliflen der Nr. 1.2.3.5. 6 und der Artelakte aus Sericitschiefer bildet er schuttartige Anhüulungen von unregelmässigen, meist rundlichen Körnern, kommt aber auch in kleinen, 0,015-0,13 $\mathrm{mm}$ langen und $0.005-0,04 \mathrm{~mm}$ hreiten Kryställchen vor, die selten Endbegrenzung durch zwei Flächen zeigen. Bei den grösseren Kryställchen lässt sich die bekannte Riefung parallel der Verticalachse und eine Absonderung nach OP beobachten, die sich bis zur Trennung der Krystalle steigern kann. Eine andere A usbildung des Zoisits gewahrt man im Gestein Nr. 7. Hier bildet er als wesentlicher (iemengteil grössere zackige, eckige und lappige, meist etwas trühe Körner von gelblicher his ölgrïner Farbe. Diese Eigenfïrbung modificirt auch seine Polarisationsfarbe, welche ein schönes violblau ist. Der in diesem Gestein so reichlich auftretende Muscovit (s. o.) ist mit dem Zoisit teils parallel verwachsen, teils regellos um ihn angeordnet. Eine Psendomorphose von Muscovit nach Zoisit aus dem Granit des Fichtelgebirgses heschreilut R. B I um im N. Jahrb. f. Mineral. 1868 S. 806,8. In den Schlillen des Handstücks $\mathrm{Nr} .7$ von 'Te Raki ergeben sich viele mikroskopische Anhaltspunkte für eine gleiche Pseudomorphose im Kleinen. Es zeigen nïmlich die im gewöhnlichen licht homogenen und gleichmässig gefirrbten Zoisitkörner unter gelirenzten Nicols vom Rande aus nach innen zu und auf ihren Spaltrissen einen allmälılichen Übergang in Muscovit Joch wurde auch eine I'mwandlung des 
Zoisit in umgekehrter Richtung beohachtet. Bei in sich gleich feschatfenen Körnern ergibt die Anwendung des parallel polarisirten Lichtes, dats das eine Ende eines Korns noch aus '\%oisit, las andere ans Muscovit hesteht, wohei die sonst nicht wahrnehmbare (irenze zwischen beiden Mineralien dentlich sichthar wirel. Der Zoisit weist stets undulöse Auslöschung auf, die sich mununterhrochen in grösseren und schattenhalten I'mrissen durch indie umgebende, aus ihm entstandene Muscovitsubstanz fortsetzt. 1. Die Beobachtungen dieser Psendomorphose wurden an einwandfreien l'artien des sichliffes gemacht und zwar an solchen, wo nicht etwa beide Substanzen über einander lagen.

Graphitoid tritt ebenfalls als wesentlicher Gemengteil im Gestein Nr. 7 aul, welchem er eine schwarze Färbung verleiht. Auf schieferungs- und aul (iesteinsalosonderungsllichen ist er metallisch glinzend und aihnelt daun dem (iraphit. Doch verbrennt die völlig amorphe und spröde Substanz auf Platinblech leicht und hinterlïsst eine hetrïichtliche Menge roter Asche. In der Reduktionsflamme des Löthrohrs verkokt sie mit silberglänzender Oherflïche. Sïuren und Alkalien haben keinen bemerkbaren Einfluss. Eine Aschen-Analyse des (iesteins ergab eine Gewichtsdifferenz von $8{ }_{1}^{1} \%$, welche den Anteil der verbrennbaren bituminösen Substanz darstellt. Sie liegt zum grössten Teil als staub auf den sichieferungsllichen und häut sich an einzelnen Stellen dermassen an, dass sie die darunter liegenden Quarz- und Glimmerkörner verdeckt. Sie dürfte mit dem von Sa uer. in der Zeits. d. Deutschen Geol. Ges. XXXVII 1885 auf $\therefore 411$ beschriebenen Graphituid aus den Glimmerschiefern des Erzgebirges identisch sein.

Helminth stellt sich in korkzieher- und wurmähnlichen Gebilden im Sericitschiefer Nr.5 ein; er zeigt etwas Pleochroismus von farblos bis hellgrünlich, geringe Doppelbrechung und niedrige Polarisationsfarben. In einzelnen Sichlifien findet sich relativ viel einer chloritischen Substanz, wie man sie in den Diabasen so häufig triflt.

Zirkon ist reichlich vorhanden und gibt gern Veranlassung zu centrischer Anlagerung von Quar\%- und Feldspatkïrnchen. Er kommt in scharf begrenzten, lathlesen lirytallen von $1 / 4 \mathrm{~mm}$ Läinge und in der üblichen Combination vor, meist 
aher findet er sich als nellienlraune süulenförmige Körner mit deutlichen prismatischen Blätterbrüchen.

Der Epidot ist in Körnern von gelblicher Farbe regellos im Gestein verteilt. Nit Vorliebe zwängt er sich in die Zwickel der die centrische Struktur beim Feldspat bildenden Mineralien ein.

Aktinolit ist spärlich in dünnen an den Enden aufgefaserten Prismen vorhanden und häult sich gern auf den Schichtflichen an.

Der 'Titanit findet sich reichlich in runden Körnern und in den bekannten spitzwinkligen Krystallen von hell- und rotbrauner larbe.

Als Gran at sind einige unregelmïssige Körner eines farblosen, stark lichthrechenden isotropen Minerals zu deuten, aut deren Spaltrissen sich glimmerähnliche Zersetzungsprodukte zeigen. Im Schlilf des Gesteins Nr. 7 finden sich einige hellgrüne Granatkörner.

C a l c i t körner und Calcittrümerchen sind keine allzu seltene Vorkomnisse in den Sericitschiefern.

Von Eisenerzen ist neben wenig Magnetit, der in mehr oder minder scharfen Krystallformen aultritt, noch Pyrit in Würfeln von $0,42 \mathrm{~mm}$ Seitenlänge zn nennen, die in Eisenoxyd verwandelt sind.

\section{Eruptiv-Gesteine.}

Die Stufe $\mathrm{P} 6^{a}$ stellt ein kleines viereckiges -Bruchstück eines dunkelgranen harten und dichten Eruptivgesteins vor, in dem man mit blussem Ange nur einige millimetergrosse Feldspïte erkennt. Die mikroskopische Untersuchung lässt eine feinkörnige mikrogranitische, wesentlich aus Feldspatsubstanz und wenig Quarz hestehende, gelegentlich fluidale firundmasse erkennen. In ihr liegen weinrote, rundliche Zirkonkörner und Apatit in hasgrün gefärbten langen Prismen. Jetzterer kommt in den trüben, idiomorphen Plagioglas-Einsprenglingen ebenfalls und zwar als Einschluss vor. Diese sind von säulenlörmigem Ilabitus und entweder nur nach dem Alhitgesetz oder nach dem Periklinund Alhitgesetz zugleich ver\%willingt. Etwas gebleichter Biotit ist in wenigen rundlichen grangrünen Schuppen rorhanden. Ein 
das Gestein regellos durchziehendes zerfetztes, auch büschlign struirtes Eisenerz scheint das Proulukt des zersetzten (ilimmers zu sein. Die Analyse ergab einen Kieselsïuregehalt von $60,4: 2 \%$, sodass danach das Gestein als ein glimmerführender Andesit anzusehen ist.

Von anderen Ergussgesteinen kommen auf den C'hathaminseln Feldspatbasal te und II ag ma hasal te vor. Nephelinbasalte, in denen der Nephelin nur als Füllmasse auftritt, finden sich unter den von sich a u ins sand mitgehrachten wenig zugehauenen Hud roh zugerichteten Artefakten (vgl. S.6). Ebenso ist darunter ein Trachyt. Nephelinbasalte von der Ostküste der Südinsel Neu-Seelands beschrieb Ulrich (Lit. Nr.6).

Die Basalte werden durch 7 Stücke repräsentiert, von denen $\mathrm{Nr} .27^{\mathrm{b}} \mathrm{schlackiger} \mathrm{Natur}$ ist, während $\mathrm{Nr} .17 .19$. 43 feinkörnige und die Nr. 37-39 grobkörnige und hornblendeführende Feldspatbasalte sind.

$\mathrm{Nr} .27^{\mathrm{b}}$ ist eine am Waitangi-Strande aufgelesene poröse braunrote $\mathrm{L}_{\text {a }} \mathrm{va}$, in deren u. d. M. feinkörnigen, schwarzen und undurchsichtigen Schlackensulstanz fluidal angeordnete P'lagioklasleisten mit reichlichem Magnetitstaul, nelsen einigen zwischen sie eingezwängten Augitkörnchen liegen.

Die Basalte Nr. 17 von der Insel Rangatira in der Lagune und Nr. 43 rom Strande hei Te One sind dichte grauschwarze gl im merführende Basalt e ron holokrystallin-porphyrischer Struktur. I)ie recht feinkïrnige (irundmasse wird ron triklinen Feldspatleisten mit ausgezeichneter Fluidalstruktur, dann von farhlosen, manchmal hellgrünlichen, winzigen nie üher $0,03 \mathrm{~mm}$ lang und $0,01 \mathrm{~mm}$ breit werdenden Augithrystäldchen sowie ron Magnetitkryställchen und Körnchen gehildet. Idiomorpher zonar aufrebater Plagioklas tritt als seltener Linsprengling auf. Olivin fehlt ginzlich. Apatit wurde in einigen länglichen Xadeln angetrollen. Rothrauner Biotit, gelegentlich in Kirystallform, stellt sich als reichlicher Gemengteil in (2)uer- und Jingsschnitten ein und zeigt startie Absorption ron hellgelh his dunkelhraun. Er ist älter als der Augit, doch bleibt es zweifelhaft, ob er als Einsprengling anzusehen ist. Seine ganze Erscheinungsweise ist mehr die eines firundmassengemengteils und sein Verhältnis \%um 
Plagioklas in der Grundmasse etwa wie 1:5. Der K ieselsäuregehalt dieses Basaltes (Nr. 43) betrïgt 48,5\%. Nr. 19 ist ein dichter etwas pechglïnzender Feldspatbasalt von holokrystallin-porphyrischer Struktur, in dem man schon mit blossem Auge Olivinkörner wahrnimmt. Die Grundmasse besteht aus Plagioklasleisten, blassrosafarbenen Augitkrystallen und unregelmïssigen meist zersetzten Olivinkörnern. Diese haben Anlass zu Neubildungen von grüner Farbe und von büschliger auch radialstrahliger Struktur gegeben. Magnetit in Körnern und baumförmigen Dendriten, wie auch Ilmenit in schmalen Leisten beteiligen sich an der Grundmasse. Als Einsprenglinge sind idiomorphe, recht grosse und von den Atmosphärilien bedeutend weniger angegriffene Olivine, sowie violette, wohl titanhaltige idiomorphe Augite zu nennen. Letrtere sind oft ron trüber Grundmasse und von durchsichtig braunen Glaseiern erfüllt. Die Grundmasse zeigt oft ophitische Struktur.

Die restlichen drei grobkörnigen Feldspathasalte (= Dolerite, Ilaüy) Nr. 37 von Whakekauri, Nr. 38 vom Hutt-Hafen und Nr. 39 von der Nähe des Mount Dieffenbach führen in einer Leucit- und Nephelinfreien holokrystallinen aus Augit, Feldspat und Olivin bestehenden Grundmasse Einsprenglinge von Hornblende, Augit und Olivin. Die Cirundmasse besteht aus rosatfarbenen bis violetten etwas pleochroitischen Augitkrystïllchen und aus bis zu $0,12 \mathrm{~mm}$ langen und $0,012 \mathrm{~mm}$ breiten Plagioklasleisten, die sich mit Vorliebe zu sternartigen Aggregaten zusammenthun oder sich auch wohl zu mehreren aneinanderreihen. Die Grundmasse wird ferner aus unregelmïssigen Olivinkörnern gebildet, die fast stets zu Eisenhydroxyd oder zu grünlichen die Gesteinshohlrïume erfüllenden Neubildungen verändert sind. Magnetit in Krystallen und in dendritischer Ausbildung, sowie Ilmenit in feinen lïnglichen Leisten und in bis $7.15 \mathrm{~mm}$ grossen Lappen beteiligen sich an der Grundmasse. Apatit wurde in einigen stauherfüllten Säulchen angetroffen und gleichfalls einige randlich angeschmolzene und mit einem Porrizinsaum umgebene (Yuarkörner. Die Ilornblende- und Augit-Einsprenglinge sind von $5 \mathrm{~cm}$ Höhe und $3 \mathrm{~cm}$ Breite und die Olivine werden bis $2 u 2 \mathrm{~cm}$ gross; von der Verbreitung der 
ersten heiden Mineralien in den Basalten gieht ein $10 \mathrm{~cm} x$ $7 \mathrm{~cm}$ grosses Handstïck den rechten Begrifl. In diescm liegen nicht weniger als drei Individuen der ansgezeichnet prismatisch spaltenden Hornblende und zwei des weniger spaltharkeit besitzenden Augits. als 5 cm grosise Einsprenglinge. Das spez. (iew. der in splittern ror dem böthrohre ziemlich leicht schmelzenden Hornblende ist 3,239, das des schwieriger schmelzharen Augits 3,372. Wihrend beim letzteren Pleochroismus fehlt, zeigt er sich bei der Hornhlende recht stark und zwar von dunkellraun in der Richtung der kleinsten Elasticititsaxe c üher gelhlichgrün bis hellgelb in den Richtungen der anderen Achsen. Die Hornblende ist stets mit einem bis zu $1 \mathrm{~mm}$ breiten Corrosionssaum umgeben, der beim Augit fehlt. Derselbe besteht, wie Abb. Nr.2 auf Tat.IV reigt, aus linglich zakkigen Ihnenitleisten und hellrosafarbenem unter sich optisch gleich orientiertem und zugleich anslöschendem Augit (A). Diese beiden Mineralien sind so angeordnet, als ob sie aus der Hornblende (in der Abb. mit II bezeichnet) hervorspriessten. Auf der Ahhildung sieht man ferner unten links einen Augit der Grundmasse, zwischen ihm und dem Corrosionssaum ein zersetztes Olivinkorn und rechts unten die Grundmasse, aus Plagioklasleisten und kleinen Augitkrystallen bestehend. 1)ünne Hïute von sekundärem goldgelbem Glase füllen die Huhlräume zwischen dem IIornhlende-Einsprengling und Saum aus. Bei der Verwitterung färben sich diese drei Basalte rotbraun und die schwerer angreilbaren Metasilicate lüsen sich aus dem (iesteinsverbande und liegen dann massenhaft in solch riesigen Individuen am Buden herum, wie sie ja in gleicher Entwicklung an vielen P'unkten der Erde rurkommen, so z. B. nordïstlich von Marburg bei Seigertshausen im Kinüllgebirge. Die Gesteine sind demnach hornblendeführende Feldspatbasalte. Von nenerer litteratur hierüber nenne ich:

F. Becke, Gesteine der Columbretes (Min. u. petrogr. Mitteil. Wien 1897, XVI S. 327 und weiter der dazu gehörige. Anhang 4).

J. Hazard, Über die petrogr. Unterscheidung vou Decken- und Stielbasalten (ibidem 1895, XIV S. 297).

Ausserdem kommt noch u. a. in Betracht:

Sommerlad: Über Hornblendeführende Basaltgesteine (N. Jahrb. f. Hin. Beil, Baud II 1883). 
Die Nr. 32 und Nr. 33 vom. Mtt. Engst und Nr. 34 von Whakekauri „in Höhlen des dort anstehenden Basaltes vorkommend" (Etiquette Schauinslands) sind hor $\mathrm{n} b \mathrm{l}$ en d e f ï h r e n d e \a g mabas a t te (L i mburgite). Ich ziehe vor, für diese den äusserlichen Merkmalen des "Limburgits" (Rosenbusch) wenig entsprechenden Gesteine die Bezeichnung „Nagmabasalte“ zu gebrauchen. Ihnen fehlen die idiomorphen, leicht aus dem Gestein lösharen Augite und der makroskopische Iyalosiderit; dann sind die charakteristischen mit Zeolithen erfüllten Hohlräume durchaus nicht so entwickelt, wie an dem Sasbacher Limburgit. Die Absonderung dieser drei Gesteine von den Feldspatbasalten erfolgte aus systematischen Gründen. Vielleicht ergiebt eine spätere örtliche und gründliche geologische Untersuchung der Lagerungsform und speziell der Frage, ob diese 3 Gesteine vielleicht nur Partieen der Stromoberfliche sind, dass die Abtrennung eine zu willkürliche war. Es ist möglich, dass diese Magmabasalte einem basaltischen Erguss angehören und vielleicht nur schnell erkaltete, glasreichere und deshalb feldspatärmere Feldspatbasalte sind. Überdies führt Nr. 34 etwas Feldspat. Meine Annahme, dass beide Cresteinsfamilien in einander übergehen können, wird durch das in Rosenbusch's Gesteinslehre 1. Aufl. auf S. 364 erwähnte Beispiel in der Montagne Noire unterstützt.

Die Grundmassen dieser drei Magmabasalte sind verschieden, ich werde sie bei jedem Stück einzeln beschreiben. Gemeinsam sind ihmen aber porphyrische Hornblenden und Augite. Während diese schwarzen makroskop ischen Hornblende-Einsprenglinge in dem grünlichgrauen ausserdem noch mikroskopische Hornblende führenden fiestein $\mathrm{Nr} .33$ nicht über $1 / 2 \mathrm{~cm}$ gross sind, erreichen sie in den schwarzen, \%. Theil pechglinzenden Magmabasalten Nr. 32 und Nr. 34 Dimensionen von $2 \mathrm{~cm}$. Ferner kommt in den letzten beiden noch ein bis zu $1 \mathrm{~cm}$ grosser schlackiger mit einer bläulich schimmernden Haut überzogener Augit vor, der ebenso wie die Hornblende keine Krystallhegrenzung besitzt. Immerhin bleiben aber beide betrichtlich hinter der (irösse der Ifornblende- und Augit-Einsprenglinge der Feldspatbasalte $\mathrm{Nr} .37-39$ zurïck. 
Während nun das grünlichgraue Gestein $\mathrm{N} r .33$, welches von vielen mit Aragonit erfïllten Ihohlräumen durchzogen wird, insofern eine Sonderstellung einnimmt, als es nur aus einer Giasurundmasse, die teilweise entglast ist, und aus mikroskopischen und makroskopischen Hornblende-Einsprenglingen besteht, tritt uns in dem bläulichschwarzen, hei Verwitterung sich bräunendem Gestein Nr. 32 ein typischer Nagmahasalt entgegen. Er zeigt einige leere Hohlrïume, ist feldspatfrei, und von demselben Fundort wie Nr.33, nämlich vom Mt. Engst. - Stufe $\mathrm{Nr} .34$ stellt dagegen ein kompaktes, mattes, an grossen porphyrischen Hornblenden und ehenso grossen schlackigen Augiten hesonders reiches grohkörniges Gestein dar, welches nach den äusseren Merkmalen dem Feldspathasalt Nr. 38 völlig gleich zu sein scheint. Es führt auch etwas mikroskopischen Feldspat. Trotzdem sehe ich es ebenfalls als einen Magmabasalt an, der zwischen dem typischen Magmabasalt $\mathrm{Nr} .32$ und den oben beschriebenen Feldspatbasalten steht, auf (irund des mikrostiopischen Befundes aber zu ersteren zu stellen ist.

Was nun die mikroskopische Untersuchung der 3 Magmabasalte betrift, so ergielot diese für $\mathrm{Nr}$. 33 ein gellhraunes bis grünliches schwammartig poröses, in IIC'I nur teilweise lösliches Glas als Grundmasse, aus dem sich darin schwimmende unbestimmbare Mikrolithen ausgeschieden haben. In ihr liegen ausser den bereits erwähnten centimetergrussen Hornblende-Einsprenglingen noch solche von $0,4 \mathrm{~mm}$ Höhe und $0,3 \mathrm{~mm}$ Breite, die ron unregelmässiger Begrenzung sind. Sie besitzen stets einen schmalen opacitischen Corrosionssium. Einigemale wurden einfache Zwillinge nach (100) heobachtet. Aul den Hohlrïumen dieses Gesteins ( $\mathrm{r}$. 33) hat sich Aragonit in radialstrahliger Struktur abgeschieden und zeigt das schwarze Kreuz. Das Gestein ist daher ein glasreicher hor nblendef ïhrender Magmabasalt.

Die Grundmasse der Nr. 32 dagegen besteht aus einem nur zum kleineren Teil in IIC' löslichen Glase von braunschwarzer Farbe. Dendritische Ausscheidungen eines schwarzen Eisenerzes durchspicken die Grundmasse in schmalen langen I,eisten, welche sich auch baumförmig struiren und damn von einem Haupt- 
arm aus in senkrechter Richtung mehrere kleinere und feinere Leistchen entsenden, die aber dann nur einseitig auftreten. Diese auf Inmenit dentenden Individuen messen $0,12 \mathrm{~mm}$ in der Länge und oft nur $1 / 1000 \mathrm{~mm}$ in der Breite. Die Grundmasse des Magmabasaltes Nr. 32 wird ferner von einem Wirrwarr von violetten Augitprismen gebilıt, deren Grössenverhältnisse $0,12 \mathrm{~mm}$ in der Länge und $0,025 \mathrm{~mm}$ in der Breite betragen. Ausserdem kommt noch in reichlichem Nasse als Bestandteil der Grundmasse ein regelmässig begrenzter Olivin vor, dessen kleine Individuen scharfe Spaltrisse und einen besonders hohen, bei der Verwitterung sich bemerkhar machenden Eisengehalt besitzen und danach wohl Iyalosiderit sein dïrften. Ausser den auf S. 20 genannten grossen Hornblende- und Augit-Einsprenglingen wurden in diesem Magmabasalt keine weiteren und erst unter dem Mikroskop erkemubaren porphyrisch auftretenden Mineralien, wie es in Nr. 33 der liall ist, beobachtet. Nr. 32 ist ein hornblendeführender. Magmabasalt.

bie Crundmasse des Magmahasalts Nr. 34 wird überwiegend von einem ebenfalls nur zum kleineren Teil in HCl auflöslichen Glase gebildet. An ihr beteiligen sich ausserdem noch hellbrïunliche auch violettgefärhte Augite, wenige Feldspatleisten und Magnetit. Das ursprünglich braunschwärzliche Glas geht bei Verwitterung in ein sekundäres goldgelbes über, das die Gesteinsporen erfüllt. Augitsonnen sowie mit einem Porrizinsaum umgebene und teilweise eingeschmolzene Quarzkörner sind nicht selten. Einige wenige unregelmässige, farblose und zur Grundmasse gehörige Körner mit lehhafter Doppelbrechung und hohen Polarisationsfarben wären als Olivin $z u$ deuten. Auch finden sich in diesem Magmabasalt noch die auf Taf. IV Nr. 3 abgebildeten Umwachsungen von Enstatitiörnern durch violettfarbenen monoklinen Pyroxen. Ersterer charakterisiert sich durch seine feine Spaltrisse, grade Auslöschung und stets eisengraue Polarisationsfarbe. Im Kontakt mit dem ihn umhüllenden und Krystallform bildenden Augit hat sich um den Enstatit ein opacitischer Saum einer schwärzlichgrünen, feinkörnigen, krystallinischen Substanz gebildet. Auf der linken Ilälfte der Abbildung sieht man einen zerbrochenen Augitkrystall, dessen 
Kern larmlos his hellgrau ist, während die limble violette Farhe hesitz. Spaltrisse durchziehen ohne Interhrechung diese beiden krystallographisch gleichen aher chemisch wohl rerschiedenen Substanzen, die auch verschieden hohe Auslïschung anfweisen. Ausser diesen beiden zu den mikrosknpischen Einsprenglingen zu rechnenden rhombischen und monoklinen Pyroxenen und den auf s. 20 beschriebenen makrostiopischen porphyrischen Hornblenden und Augiten findet sich noch mikroskopische Hornhende mit recht starkem Pleochroismus von dunkelbraun bis hellgelh. Dieselhe weist vereinzelt Krystallflichen auf und ist nach der ${ }^{\circ} c$-Achse gestreckt. In einem dieser kleineren Hornhende-Einsprenglingen beohachtete ich die von va n W erveke im N. Jahrb. f. Jineralogie 1879 S. 482 beschriebenen: "opalien schwarzen Nädelchen, welche regelmässig nach zwei aufeinander senkrechten gegen die krystallographischen Achsen geneigten Richtungen der Hornblende eingelagert sind". van W'ervelie hat deren Natur nicht nachgewiesen, ich kounte sie riemlich leicht durch Salzsïure zerset\%en. Sie erreichen eine länge von $0,096 \mathrm{~mm}$ und eine Breite von $0,006 \mathrm{~mm}$. Nr. 34 ist daher ein etwas Feldspat und makroskopische sowie mikroskop ische Hornblende führender Magmabasalt.

Tuffe und trachytische Gläser.

Von Tuffen liegen die Nr. 18. 20. 42 , in der Nähe von Waitangi“, Nr. $28-30$ und 35 rom VIt. Engst und P' 1 und 3 vom Fowerpot-Hafen auf Pitt Island vor. I) ersten zwei sind hochgratig zersetzte und zerreihliche feinkörnige, kalkreiche, teils thonig mergelige Palagonittulle, die Reste von Wurmröhren und von Muscheln enthalten und deshalb zum Teil mariner Bildung sein müssen. Xach Mügge's (X. Jahrb). f. Vlin. Beil. Band VIII 1893 S. 708) Einteilung wären sie als palagonithaltige 'l'uffoide zu bezeichnen. Ihr Eisengehalt ist ausgelangt und als schaliger Eisenstein (s. u. auf S. 27) in den T'uffen lagenförmig wieder alogesetzt worden. I) Tulfe $28-30.35 .4 \%$. I' I und 3 sind fester, grohkörniger und weniger durch die Verwitterung verïndert. 
Auf frischem Bruch zeigen diese äusserlich dunkelbraunen und rotbraunen echten Palagonit-Tuffe einen schwarzen pechglïnzenden Kern. Sie umschliessen unregelmaissig gestaltete mehr oder minder verwitterte schlackenartige Basaltstïckchen und kleine Bomben, dimn auch grössere fragmente der in den Basalten Nr. 37-39und Magmabasalten Nr. 32-34 ebenfalls angetroflenen und dort beschriebenen Augite und IIornblenden, sowie Fragmente von schwarzem Gilimmer. I. d. M. sieht man, dass die frischeren Tuffe aus rundlichen Lapilli eines braunschwarzen an I)ampfporen reichen Glases bestehen, soweit sie nicht thonig und zersetzt sind. Das Glas umhüllt auch die erwähnten Mineralfragmente und verkittet die einzelnen Lapilli. Ihre Verwitterung beginnt zunächst randlich, schreitet nach innen auf den Sprüngen und Hohlräumen unter Bildung von Zersetzungsprodukten fort und bildet schliesslich hellgelbe und hellgraue thonigmergelige gegen das polarisierte licht indifferente Sulstanzen. Das im frischen Zustande schwarze undurchsichtige (ilas brïunt sich, scheidet also Eisenhydroxyd ab, geht damn in ein klares goldgelhes Glas über und wird schliesslich trübe. Seine zahllosen Poren vergrössern sich und füllen sich mit aggregatpolarisierendem kohlensaurem Kalk und zierlichen langen Nalehn eines Zeolithes. I)ieser ist in verdünnter $\mathrm{HCl}$ löslich, enthält viel $\mathrm{Na}$ und dürfte wohl Natrolith sein. Zugleich lösen sich die widerstandsfähigeren Einsprenglinge - Augit und Olivin - aus ihrem Verbande. D)as oft ausgezeichnete Fluidalstruktur zeigende Glas der Lapilli ist entweder frei von Ausscheidungen, wie das der Nr. 18 und 20, oder es enthält mikrolithische Entglasungsprodulite. Diese bestehen aus in den Lapilli kolonienweise angehäuften Augitmikrolithen, die bei völliger Krystallaushildung von solcher Feinheit sind, dass bei 350 facher Vergrösserung durch Drehen der Mikrometer-Schraube bis zu 3 Individuen eins über dem andern liegend hervortreten. Sie sind oft nur $0,002 \mathrm{~mm}$ lang. - Grössere oft Zonar- und Sanduhrstruktur zeigende nach (100) einfach und vielfach verzwillingte Augiteinsprenglinge schwimmen in dieser Grundmasse und sind von schwarybraunem wie rotem Glase in Gestalt von Eiern erfüllt, das sich auch noch auf den Blätterbrüchen einzwängt. Es bilden sich auch aus 15 und 
mohr Angit-Individuen bestehende Sumen. Gusetzmïssign Verwachsungen ron monoklinem und einem brïnlichen rlomblisehen Pyroxen wurle einige Male heohachtot. Der stets porphyrische OJivin bildet auch in diesen hapilli die ältere Ausscheidung und ist stets idiomorph. Er ist meist noch frisch und klar und nur vereinzelt rom Magma korrodiert worden. Eine beginnende Zersetzung reigt sich bei ihm durch eine feine von den Spaltrissen ausgehende dendritische Brïnnng. Olivinzwillinge wurden mehrfach beobachtet. Wiihrend ein Beispiel der von Cohen (N. Jahrh. f. Min. 1880 II. s. 5.3) leschriehenen sich rechtwinklig durchkreuzenden und nach den Nicolhanptschnitten ausloischemden Penetrationszwillinge vorhanden ist, treten anch Juxtapusitionszwillinge aut; ihre unsymmetrische latge lässt es zweifelhaft, oh bei letzteren das zuerst von Kalkowsky aufgefundene Giesetz nach (011) in Betracht kommt. Der Glimmer ist nur in wenigen dunkelbramen stark pleochroitischen lappigen fndividuen vorhanden und ein Übergemengteil. Feldspat kommt in diesen Tuffen und ihren Gläsern nicht vor. Haghetit ist reichlich vorhanden. Es sind mehr oder minder zersetzte Palagonittuffe.

Nr. 42 ist ein hühnereigrosses Strandgerölle, das zum grössten Teil aus palagonitischem Tulfmaterial hesteht; dies ist durch ein feinkörniges radialstrahligfasriges Kalkkarbonat verkittet.

Nr. 35 stellt eine rotbraune feinkörnige poröse Schlacke dar, die das gleiche mikroskopische Bild zeigt, wie es sich dem unbewaffneten Auge bietet. Die Hohlräume sind durch feinfasrige Mineralien ausgepolstert.

$\mathrm{Nr} .47^{\text {a }}$ enthält weisse und schwärzlichgraue am Strande bei Te One gefundene Trachytbimssteine (Zirkel). Der weisse ist ein reines Gilas mit einigen Plagioklaseinsprenglingen, währent der graue his zu $2 \mathrm{~cm}$ grosse porphyrische Auscheidungen führt und aus einem Vetwerk eines hasigschamigen, reeht festen schwarzen Gilases hesteht, dem schwarzer vullinnischer staul, und bituminöse Substanz die Fürbung verleihen. Beim Erhitzen decrepetirt er heftig, bläht sich vor dem luötrohr auf und brennt sich weiss. In den glasigen $W$ änden der Poren liegen viele rundliche und elliptisch atusgezogene hald rot wher geth, 
bald grün, jederzeit aber anders gefïrbte Glasthränen. Idiomorpher his $\% 0,0,25 \mathrm{~mm}$ grosser von Augitnädelchen poikilitisch durchwachsener Orthoklas und polysynthetisch verzwillingtes l'lagioklas sind dem im reflektirten Licht seidenglänzenden Glast eingesprengt, ebenfalls etwas Magnetitstaub; analytisch wurde (ilciumkarbonat nachgewiesen. Die erwähnten porphyrischer Ausscheidungen besitzen panidiomorph-körnige Struktur unc bestehen aus meist verzwillingtem Feldspat, sehr viel Magnet. eisen, und vor allem aus einer stark pleochroitischen lauchgrüner langprismatischen Itornblende, deren Auslöschung von geringer Schiefe ist. Oft ist sie zu drei und mehr Individuen stern- unc bïschelförmig struiert, an den Polen aufgelasert und nach (100, verzwillingt. Ein feiner Eisenerzstaub erfüllt diese $0,1 \mathrm{~mm}$ langen und $0,02 \mathrm{~mm}$ breiten Prismen, die als Einsprenglinge in Glase selbst fehlen, und nur in den Secretionen und danı scheinbar darin angereichert vorkommen.

\section{Schichtige Gesteine.}

Aufdem Wege rom MIt. Engst nach Te ()ne und zwar hinter Te Rak am Westkap findet sich in ausgedehntem Naasse ein weisser poröser doch fester und rauh sich anfühlender Kieseltuff von 2,5? Dichte. Er besteht aus einer gleichmässig feinkrystallinischer Kieselsulistan\%, der einige Feldspatkörner beigemengt sind. Diє Ergebnisse einer unvollstïnảigen Analyse sind:

$$
\begin{aligned}
& 92,40 \mathrm{SiO}_{2} \\
& 0,51 \mathrm{Fe}_{2} \mathrm{O}_{3}+\mathrm{Al}_{2} \mathrm{O}_{3} \\
& 1,63 \mathrm{H}_{2} \mathrm{O} .
\end{aligned}
$$

D)ieser Kieseltufi' enthält ferner ('aO und $\mathrm{MgO}$. I) ie Tremnung vor: Thonerde und Eisenoxyd erschien unwesentlich und unterblieh

Kalk- und Eisensteine, Sandsteine, Thone und Il eeressand.

Nr. 8 und 9 sind zum Teil aus Kalkalgen und Bryozoen aufgebaute weisse mehr oder weniger hompakte Kalksteine, die ausserdem noch Reste von diatomeenartigen Gebilden enthalten, und - die nach Scha u inslands Mitteilungen auf den C'hatham-Inseln 
ehr verbreitet sind. Ilerr Prof. Dr. Kohl-Marburg hatte die iüte, die Anwesenheit von Kalkalgen lie unter c) auf Seite 10 erwähnten Kalksteine. Nr. 10 und 11 on den Red Bluffs, 12 vom Lakie Huro, P 5. 7. 8 von Pitt sland stellen die auf Seite 9 unter a) besprochenen kompakten veisslich, hellgelblich bis chamoisfarbenen kalksteine dar, lie Spongienreste, Bryozoen und Echiniden (siehe unter D) feite 57) enthalten und mit den Stacheln einer mit Cidaris ferticillata Lam. verwandten, wahrscheinlich kretaceischen Art orfüllt sind. Nr. 31 ist der auf Seite 10 unter b) erwähnte weiche weisse und gelbliche Kalkstein; er kommt vor am Ftrande des Mit. Engst, bei Tioreors und bei Whakekauri; er ist mit dünnschaligen Gryphaeen, mit grossen Pecteniden sowie mit Resten von Globigerinen und Radiolarien erfüllt, und als jungtertiär anzusehen. Nr. 14 ist ein noch Wurzelfïserchen umschliessendes Osteocoll von der Waitangi-Bucht, Nr. 22 ein radial fasriger Kalkstalaktit von $15 \mathrm{~cm}$ Länge mit konzentrischen Anwachsringen ehendaher und Nr. 21 sind von ebendort stammende Konkretionen von Calciumcarbonat, wie man sie in den Tuffen findet. $\mathrm{Nr} \cdot 13$ ist eine Stufe der rezenten weit verbreiteten Kalksteinablagerungen, die aus Korallen, Bryozoen, Muschel- und Schneckenschalen (darunter besonders häulig Vermetus-(iehäuse) bestehen und Nr. 21 stellt einen dunkelgrïnen kalk- und glaukonitreichen Sand dar, der ebenso wie Nr. 13 von der WaitangiBucht kommt. $\mathrm{P} 6^{\mathrm{b}}$ ist ein faustgrosser Knollen von gelblichweissem dichtem $\mathrm{Mag} \mathrm{n}$ es it unbekannten Ursprungs.

Die $\mathrm{Nr} .23^{2}$. 25 und 26 sind Kalksteine, in denen eckige und abgerollte kleinere Feldspatbasalt- mol Magmahasalt-Brocken, etwas glaukonitischer Sand, dann Fragmente von Feldspat, von Quarz, von Augit und Chlorit neben Resten niederer Tiere liegen. Sie kommen in der Waitangi-Bucht und bei Whakekauri vor.

1)ie Nr. $23^{b} \cdot 24,27^{\text {a }}$ und $\mathrm{P} 2$ sind dunkelrote und brane schalige Eisensteine mit traubig-nieriger Oberfläche, die als sekundäre Bildungen in den Tullen des Mangahu-Baches und bei 'T'e One gefunden worden. Ihr Wassergehalt schwankt zwischen 5,1-10\% o. Sie müssen einen hohen Eisengehalt und 
Nutzwert haben, da sie nicht durch Chrom, Thonerde und Kieselsäure verunreinigt sind und Mangan nur in geringer Menge enthalten. Zwischen den einzelnen $1 \frac{1}{2} \mathrm{~cm}$ starken Schaalen haben sich kleine irisirende Kiryställchen von Eisenglanz angesiedelt.

Nr. 44 ist ein von Te One stammender $\mathrm{Sch}$ we felkies$\mathrm{knollen}$ von $3 \frac{1}{2} \mathrm{~cm}$ Durchmesser und von radialstrahliger Struktur. Nr. 48 besteht aus Pyritaggregaten, die auf Wurzeln aus den Torfmooren aufsitzen.

Nr. 4 und $40^{\mathrm{b}}$ sind graue feste Sandsteine von sehr feinem Korn, die als Wetzsteine benutzt werden und durch bituminöse Substanzen etwas gefärbt sind. Nr. 15 und 16, bei den Red Bluffs und an der grossen Lagune gefunden, sind hellgelbe bis rötliche sandige $\mathrm{L}$ eh $\mathrm{me}$, die als die accumulativen Verwitterungsprodukte der Eruptivgesteine und Tuffe anzusehen sind und deren Kieselsäure sich zum Teil als Opale u. s. w. abgesetzt hat, die wir im Folgenden besprechen werden.

In Nr. 49 und 50 liegen Proben von Meeressand von Te One und von der Lagune vor, die ausser Quarzkörnchen, viel Magnetit und Ilmenit noch Bruchstücke von rhombischen und monoklinen Pyroxenen, etwas Granat und Flussspat sowie einige abgerundete Zirkonkryställchen und organische Reste enthalten.

Opal, Eisenkiesel, Hornstein und Jaspis sowie Feuersteine.

Ein leberbrauner, schwarz und weiss gebänderter, an den Kinten durchscheinender, fettglïnzender () pal $\mathrm{Nr}$. $47^{\mathrm{b}}$ von 2,537 spez. Gew. liegt rom Strande hei Te One vor. Er löst sich nur zum 'Teil in Kalilauge, zeigt u. d. M. ausser der isotropen Opalsubstanz einige unregelmässige Körner von (Quarz und von bräunlicher Hornblende, und gehört demnach unter die gemengten ()pale (Behrens, Sitzungs.-Ber. d. kaiserl. Akad. d. Wissensch. Wien 1871 Dezhr.-Heft). Von gleichem Fundort kommt hell- und dunkelbraun gebänderter Eisenkiesel mit scharf splittrigem Bruch und 2,59 spez. Gew. Das Mikroskop enthüllt winzige concentrisch aufgebaute durch Eisenoxyd gefärbte ( ) u a r z o o l it the 
von nur $0,02 \mathrm{~mm}$ Durchmesser neben radialstrahligen $1 \mathrm{~mm}$ starken und Aggregatpolarisation zeigenden Chalcedonsphärolithen. Ich vermochte nachzuweisen, dass die Fasern der letzteren optisch negativ sind, doch gelang es mir nicht, die Zweiachsigkeit der Substanz in dem freichen Matsise wir Michel Levy und M unier Chalmas (Bull. soc. franę. de min. Paris XV. 1892) zu beobachten.

$\mathrm{Nr} .45$ and $\mathrm{c}$ sind gelbliche und graue Hornste ine, die in einer mikrokrystallinischen aus feinsten (1)arzteilchen hestehemben Grundsulstanz zahlreiche scharf begrenzte (Quar\%lirystallehen $(+R .-R, \infty R$.$) , sowie einige Fragmente von Chlorit, Feld-$ spat und llagnetit neben den unter $47^{\mathrm{b}}$ heschriehenen sphirroliten enthalten. Sie umschliessen wie die folgenden Jaspisknollen zahlreiche organische lieste. Es fanden sich hiervon: nadel- und ankerfömige spiculae ron hieselschwämmen, fermer Foraminiferen und Radiolarien.

Nr. 40 und $46^{a}$ sind stransseneigrosse gelbbraune $J$ as p is $\mathrm{knollen}$. Sie sind in einzelne unregelmässige. Bruchstïcke zerborsten, die durch Quar\% wieder verkittet wurden. Wegen ihrer Härte und ihres glatten bruchs verarlseiteten die Morioris sie zu Artefikten.

$\mathrm{Nr} .45^{\mathrm{b}}$ stellt einen grauschwarzen Feuerstein mit muschligem Bruch dar, der in fein krystallinischer Grundmasse einige Feldspatleisten, ('hloritschüppchen und Yagnetit führt. Er gleicht völlig den senonen Feuersteinen Mordelentschlinds. mit denen er wohl gleichaltrig ist, da die obere Kreide durch Fossilienfunde auf den ('hatham-Inseln nachgewiesen worken ist. 
B.

\section{IDie Gesteine (ler I'Urville- Ind der Stephens-Insel, der Trio- und der Reallgitoto-Inselgruppen, sowic der Elmsley-Bay.}

Jas auf Trifel III dargestellte Gebiet liegt an der Admiralty-Bay der Cookstrasse und zwar innerhalb des 173. und 174. östl. Längengrades (von Greenwich) und unter $40^{\circ} 40^{\prime}-40^{\circ} 58^{\prime}$ südl. Breite.

Als Literatur ist $\%$ nennen:

1. F. v. Hochstetter, Reise der Fregatte Novara Geolog. Teil Bd. I, nebst geol-topogr. Atlas von Neu-Seeland von v. Hochstetter und Peterinann.

2. F. W. Hutton, Eruptive Rocks of New Zealand. Journal Royal Soc. of New South Wales. Sydney 1899. XXIII. S. 102-156.

3. Cox, Mineralogy of New Zealand (Trans. New Zealand Institute Wellington XIV, 1881).

Diese Inseln und Inselgruppen sowie das benachbarte Festland sind als der östliche Auslïufer der southern Alps von NeuSieland anzusehen, die sich bei der Provinzialhauptstalt Nelson in zwei (iebirgszïge teilen. Den östlichen hier nur in Betracht kommenden haben v. Haast und v. Hochstetter (Lit. I S. 215) besucht. Sie berichten, dass dieser Teil im Wesentlichen aus steilgestellten dünngeschichteten Phylliten und Grauwacken aufgebaut ist, denen dioritische Gesteine, Schalsteine u. s. w. eingelagert sind. Ein bis zu $4 \mathrm{~km}$ breiter Serpentinzug, der bei der Sitephens-Insel beginnt, die Ostseite der I)'Crville-Insel durchstreicht und in grader Richtung sich noch über $90 \mathrm{~km}$ weit ins Innere des Festlandes und bis über die Bahnstation Richmond hinaus erstreclit, hildet das Riickgrat des oben bezeichneten Untersuchungsgebietes. Von ihm lallen die Sichichten, welche aus den weiter unten heschriehenen (iesteinen hestehen, westlich und östlich ein, sorlass dieser Serpentinzug als dis IJ̈̈chste eines Sattels 
anzusehen ist. Am Kontalit des Serpentins mit dem Kallistein und Thonschiefer treten Reibungshreccien auf, in ihm finden sich Schollen des letzteren (iesteins, die in Kieselschiefer und in Adinolen umgewandelt wurden. Am I) un Mountain hei der stanlt Nelson enthailt der herpentinzug das bekamute D)unit-Vorkommen. unweit davon am Wooderl Peak sind ihn umlangreiche ('hromit- und Kupfererzlinsen eingeschaltet und elendort durchsetzt ihn eine his zu $20 \mathrm{~m}$ mächtige Ader ron Hypersthenfels, dessen grünlicher von Saussurit hegleiteter Iypersthen sich in (huadratfuss urusice Stücke spa!lten lïsst. Weiter nördlich und zwar zwischen Velson und der D'Urville-Insel fand v. Hochstetter (Lit. I) an der Okuri Bay des Current-Basin dolomitische von Quarzadern durchzogene Kalksteine, ehendort grünliche und gelhliche Kalkschiefer und ein rötliches bis graues von Kupfererzen und Schnüren von rotem Jaspis durchsetztes serpentinatiges Gestein. in dem Mandeln und Knauern von derbem fasrigem Epidot vorkommen. Am Strande der Okuri Bay sammelte v. Hochstetter einen Knollen Nephrit. Ich habe versucht, dieses Belegstück zur Lntersuchung zu erhalten. Doch hefindet es sich weder im K. K. Naturhistorischen Hofmusenm zu Wien, noch in den Sammlungen v. Hochstetters.

Das Alter dieser Schichten soll nach v. Hochstetters Mitteilungen, die ich etwas ausführlich wiederholt hathe, teils palaeozoisch, teils mesozoisch sein. Er erhielt (Lit. Nr. 1) von dem einzigen, bisher in der Literatur bekaunt gewordenen palaeontologischen Aufschluss, nïmlich von der südlich Velsons gelegenen kleinen Bahnstation Richmond, Kalksteine mit Monotis salinaria Schloth. und Halobia (Daonella) Lommeli Wissm. Erstere hat Schauinsland am French Pass (siehe Tafel III) in weissen dickhanking ahgesonderten Kallisteinen wiedergefunden. also an einem ungefilir $80 \mathrm{~km}$ weiter nördlich gelengenen P'unkte. Die bisher von v. Itochstetter nur auf Grund petrographischer Analogien hehauptete Zusammengehörigkeit und Cileichaltrigkeit des genannten Gebietes an der Admiralty-Bay mit demjenigen bei Richmend wird durch den Vusilienfund hestatigt. Ausser v. II a ast und v. Hochstetters Schilderungen sind mir keine anderen Arbeiten bekannt geworden. 
Herr Prof. Scha u insland hat nun im Winter 1896/1897 das weiter nördlich gelegene, in geologischer Hinsicht gleiche Gebiet bereist und sammelte:

bei der Elmsley-Bay am French Pass 9 Nummern Gesteine, abgekürzt: E auf den Trio-Inseln auf den Rangitoto-Inseln bei Tinui auf der I)'Urville-Insel an einem

Punkto, der den Rangitoto-Inseln gegenüberliegt auf der Stephens-Insel

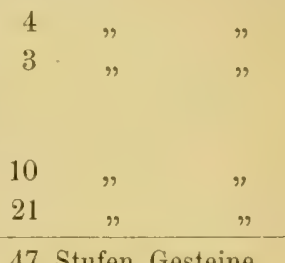

im Ganzen: 47 Stufen Gesteine.

Letztgenannter Forscher fügt aus seinem Tagebuch den obigen Angaben noch folgendes hinzu:

An der Elmsley-Bay stehen intensiv gelbe schiefrige Gesteine (E 1. 3. 4. 5. 7.9) an, die mit gleichartigen roten und grünen abwechseln. Die Felsen fallen hier elsenso, wie anf den $80-100 \mathrm{~m}$ hohen Trio-Inseln, fast senkrecht in's Meer. Die Basis der letzteren wird von den erwïhnten schiefrigen Gesteinen gehildet, während auf der Inselhöhe stark zerrissene Klippen eines (Yuargesteins ( $\mathrm{T} 2$ ) auftreten. I) as gleiche gilt auch von der Ostseite der I)'Urville-Insel, doch fehlen hier die Quarzklippen. Auf der Stephens-Insel bilden die Felsen fast senkrechte Wïnde, die in ihren unteren Partien aus dünnen grünlichen bis schwarzen (S $1-6$ und 10) überall von Quarzadern durchsetzten Thonschiefern bestehen. Im ()sten der Insel trifit man grauwackenähnliche Gesteine (S 9, 11-13.15). Auf dem Plateau der Insel, welche nur von einem Lenchtturmwärter nebst Gehülfen bewohnt ist, findet sich ein ganz weiches, tuffartiges, gelbes (iestein ron ausgesprochen schaliger Struktur (S 14. 16-18. 20, 21). Die einzelnen Absonderungen erreichen einen Durehmesser von $0,5 \mathrm{~m}$. Hier liegen auch bis manusgrosse Blïcke eines grünlichen und hläulichen Sichalsteins (S11. 12. 13. 15) umher.

Von den oben aufgezählten 47 Gesteinsstufen sind viele identisch und gehören in die gleiche Klasse. Weil sie ausserdem von einem geologisch einheitlichen und engbegrenzten 
Geliet kommen, sollen sie zusammen hesprochen werlen, mul zwar in der Reihenfolge der nummelsr folgenden Ühersicht.

\section{Übersicht.}

I. Eruptivgesteine und deren Tuffe.

Orthophyr S 7b.

Diabas oder Melaphyr T'4.

Schalsteine S 9, 11-21.

Serpentin E 1 ; U 1 und 2.

II. Krystalline Schiefer und Mineralien.

Gangquarze S 8 und T 2.

Nephrit als Gerölle in U 7 und in $S 7$. Anstehend $\mathrm{im}$ Serpentin $\mathrm{U}_{2}$.

III. Schichtige Gesteine.

Epidosit E 2 und $3 \mathrm{a}$; U 4 und 5.

Kalkepidotschiefer U 8 .

Grauwacken und Conglomerate R 1-3; U 3; E 6 und S.

Thonschiefer und Schieferthon U 6. 9; T 1. 3; S 1-6. 10; E 3b. 4. 5. 7. 9.

Jaspis und Adinolen in U 7.

Meeressand U 10.

\section{Eruptivgesteine.}

Von der nordwestlichen Bucht der Stephens-Insel lient ein hühnereigrosses fieschiehe $\left(\wedge 7^{b}\right)$ von olvengrüner farbe und splittrigem Bruch ror. In dem adiagnostischen Gestein erkennt man einige Pyritkörner. U. d. M. sieht man einige unregelmässige Einsprenglinge von trübem Feldspat in einer hellhräunlichen und durchscheinenden firundmasse von mikrosphaterulitischer struktur schwimmen. I)ie Grumbasse wirl ron hüschelförmin angeordneten hypiliomorphen und stark rerwitterten Feddspäten gehildet. Guarz als primärer Gemengteil lehlt, doch hat sich Kieselsäure sekundär auf den kliften des liestrins alugesundert, welches als ein quarzfreier Orthoklasporphyr zu betrachten ist. 
In T 4 liegt ein äusserlich braunes sonst grünlichblaues durch Dynamometamorphose schiefrig gewordenes hartes Gestein vor, das mit dem blossen Auge nichts erkennen lässt. Die mikroskopische Untersuchung eryibt, dass es ein feinkörniger Diabas oder Melaphyr mit ophitischer Struktur ist. Die daran sich beteiligenden Feldspäte sind teils gänzlich verschwunden, teils kaolinisirt, teils durch eine trübe, viriditihnliche Substanz ersetzt. Die farblosen allotriomorphen Augite hahen meist scharfe keilförmige Begrenzung, sind vielfach zerborsten und löschen ohne Ausnahme undulös aus. Sie werden oft ron einem Hof eines fasrigen Minerals umgeben, welches aus dem Augit entstanden ist und stets nur geringe Auslöschungsschiefe, lebhafte Doppelbrechung, doch nie eine ïber eisengrau hinausgelıende Polarisationsfarbe aufweist. Die Fusern spriessen meistens radial aus dem Augitkern, doch liegen sie auch in der geraden Verlängerung der Blätterbrïche. Es dürfte sich wohl um eine uralitische Bildung von Hornblende handeln. Infiltrationen des Gesteins mit Eisenhydroxỵd sind häufig und eine chloritische Substanz bedeckt oft einzelne Partien des Schliffs völlig, ahmt anderseits aber auch die Feldspatleisten nach.

Von Schalsteinen hat Schauinsland zwei Arten mitgebracht. Die Nummern S 9. 11-13. 15 stellen typische Schalsteine dar, während die Nummern \& 14. 16-21 lose und hellgelb gefïrbt sind und einen mehr pelitischen Charakter tragen.

Die ersteren 5 sind recht feste, äusserlich mit einer bis $z u$ $2 \mathrm{~cm}$ starken Verwitterungsrinde umgebene, auf frischem Bruch dunkelgrüne und blaugrüne Schalsteine. Sie sind entweder schaalig abgesondert, wie die Nr. 12. 13. 15, oder sie zeigen etwaś Schichtung und enthalten dann auch bis zu $21 / 2 \mathrm{~cm}$ grosse Gerölle von 'Thonschieferresten und von Quarz, wodurch sie den Eindruck eines C'onglomerats machen. Die genannuten drei Stulen sind von grossschaaliger Struktur und stellen etwas gestreckte Sphäroide von $24 \mathrm{~cm}$ Lïnge und $13 \mathrm{~cm}$ Durchmesser dar. Zwischen den meist $3 / 4 \mathrm{~cm}$ doch auch bis $2 \mathrm{~cm}$ starken Schaalen hat sich als Auslaugungsprorlukt Visenglanz und Eisenhydroxyd ahgeschieden. Ein Schnitt durch 


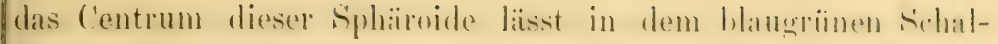
stein peripherisch angeordnete, den Jahresringen dines baumes vergleichbare, Streilen der genannten Fisenerze hervortreten, welche die äusserlich noch nicht erkennbare Absonderung der Schalen anzeigen. Diese lösen sich dann eine nach der anderen ab und liogen in grosser Menge anf dem Platean der Insel unher.

Das Mikroskop lïsst erkennen, dass diese Schalsteine ans Fragmenten von sediment- und Eruptivgesteinen bestehen, dann aus (quars und Feldspathrocken, zu denen Eisenhydroxyd Infiltrationen, viriditiahnliche Sulnstanzen und reichlicher Kallispat hinzutreten. Man sieht runde, aber auch eckige Thonschieferreste, dann gleichgeformte von Reihen unhestimmbarer Mikrolithen erfüllte (quarkörner, ferner verwitterte trübe Bruchstïcke von einfach und polysynthetisch verzwillingten leeldspäten. I)itzwischen liegen rundliche ebenfills verwitterte zur Diahasuruppe gehörige Lapillis und stark zersetzte liagmente eines. anderen basischen Eruptivgesteins. Die Natur des letzteren ist auch nicht annähernd festzulegen. Man kann von ihm nur sagen, dass verwitterte trübe und idiomorphe feldspaite in einer gänzlich zersetzten (irundmasse porphyrisch eingehettet sind. I)ie Diabaslapilli sind ebenfalls weit in der Verwitterung vorgeschritten: ihre Feldspäte, welche unter gekreuzten Nicols noch trikline Verzwilligung zeigen, sind ganz trübe und kavlinisirt, das Augitmaterial in chloritische substanzen rerwandelt. die noch Andeutungen ron ophitischer struktur zeigen. Finige in diesen Schalsteinen vorkommende mit Virilit und Eisenhydroxyd erfülte Krystallformen weisen auf ursprïngliche Olivinkrystalle hin. Accessorisch treten noch auf: Rutil in unregelmässigen Körnern, Lappen eines allothigenen etwas gehleichten aher noch pleochroitischen Biotits, einige hellrosil gefirbte Granatkörner und Fragmente von rhombischen Pyroxenen.

Die auf S. 34 erwähnten sieben Belegstücke eines pelitischer Schalsteins sind gelbe bis hellbraune, leicht zerreibliche, feinerdige his feinsandige (iesteine, wetche sowohl aus Tulfmaterial wie aus einer ursprünglich schlimmartigen Vlasse hestehen. I)iese schalsteine sind ehentalls in 
Schaalen abgesondert, zeigen aber ausserdem noch bienenwabenartige Struktur. Wie man auf Tafel IV Abb. 1 sieht, legen sich um einen Kern von 10-13 cm IJurchmessser bis $7 u 3 \mathrm{~cm}$ starke Schaalen, welche wiederum aus $2 \mathrm{~cm}$ hohen und ungefähr $3 / 4 \mathrm{~cm}$ dicken Pfeilerchen von unregelmässig fünf- oder sechsseitigem Querschnitt bestehen. Zwischen Schaale und Kern ist ein freier Raum; ursprünglich waren die Pfeilerchen mit dem Kern fest verbunden, beim Festwerden der Schalsteine haben sie sich vom Kern unter Zurücklassung ihres Abdrucks abgetrennt und besitzen jetzt ausser dem geschilderten Habitus noch einen etwas convexen Kiopf. Sie streben radial dem Kern $z u$ und sind ebenso wie die Schaalen, auf denen sie als ein dazu gehöriger Teil aufsitzen durch das Austrocknen und Einschrumpfen des vulkanischen Schlamm- und T'uffmaterial hervorgerufen worden. Die Rinde der Schaalen und die der Pfeiler, zwischen denen stets ein freier Raum von einigen $\mathrm{mm}$ Stärke bleilht, ist dunkelbraun und zwar etwas dunkler als das übrige Gestein gefärbt. U. d. II. ergibt sich, dass ausser den hereits beschriebenen hier aber noch mehr verwitterten Bestandteilen der auf Seite 35 besprochenen typischen Schalsteine, noch eine thonige und isotrope Substanz sich an der Bildung dieses Gesteins beteiligt hat. Man kann, wie Herr Prof. Schau ins I a nd mir schreibt, diese Schalsteinmassen mit dem Spaten leicht stechen.

Serpentin: E 1 und U 1 sowie U2! Diese drei Stufen entstammen dem in der Einleitung erwähnten Serpentinzuge. Von ihnen können die beiden ersten zusammen besprochen werden und zwar sind dies matte schwarzgrïne Serpentine, auf deren Kílüten sich ausser fasrigem fettglänzendem Chrysotil und Pikrolith noch ein violblauer unbestimmbarer Anflug findet. U 1 enthält einen geringen ${ }_{1 / 2} \%$ nicht ïbersteigenden Kúpfergehalt, der von Malachitanflügen und eingesprengten Kupferkieskörnchen herrührt. Die letztyenannten Mineralien können sich mit Nagnetit zu linsenartigen abbauw ürdigen Partien anreichern, welche früher Gegenstand eines sporadischen jetzt erloschenen Berghaus aul der I) L'rville-Insel bildeten. L'nter dem Miliroskop besitzen diese beiden Serpentine deutliche Maschenstruktur; in 
dem Inneren der Maschen finden sich manchmal hüschlige mond radial lasrige Aggregate der meist etwats gelhlichgrïnen serpentinsubstanz. Magnetit kommt sowohl in Krystallform wie in grösseren fetzen und unregelmïssigen Körmern ror und ist der firlonde Bestandteil des Gesteins. Frine ('hryotilïlerchen durchsetzen den Serpentin ganz regellos, auch sind ihm briunliche, teilweise mit einem schwarzen Erz erfüllte IJornblendesïulchen von $0,06 \mathrm{~mm}$ Länge und $0.02 \mathrm{~mm}$ Breite eingelagert. Ausserdem findet sich in ihm zersetzter I)iallag, der polysynthetische Zwillingsbildung mit ahwechselnd breiteren und schmilteren schon im gew. Licht bemerkbaren Lamellen zeigt. Dieses Mineral weist neben der durch Verwitterung entstandenen geringen Doppelbrechung und den niedrigen Polarisationsfarben ein markantes Relief und eine selblich griune Eigenfärbung auf. Zwischen den tafelförmigen Individuen, welche nicht verstreut im Gestein liegen, sondern in ihm Nester hilden, hat sich etwas ('alcit alogesetz.t. Dem I)iallag sind längs den Jamellen hrïunliche Kryställchen ron säulenförmigem Hahitus eingelagert, die vielleicht Goethit sind. Das Gestein. aus dem die Serpentine entstanden sind, muss ein DiallagPeridotit gewesen sein. Serpentine, die aus einem EnstatitD)unitgestein hervorgingen. und sich am Jun Mountain, also innerhalb des gleichen sierpentinzuges finden. beschreiht Hl ut to u (s. Lit. Nr.2 auf S. 154 und 155).

Der Serpentin U2 an der D'Urville-Insel ist gelblich, auf frischem Bruche blaugrün, grobhlättrig, ron schielrigem und muschligem Bruch. In ihm fanden sich die weiter unten zu besprechenden Nephritknollen (S. 51). Der Nephrit ist dem Serpentin aber auch in scharfkantigen feinsten Fragmenten breceienartig eingestreut und diese sind dann makroskopisch wegen ihirer geringen Grösse und wegen ihrer Lmhüllung durch Serpentinsulsstanz selten zu erkennen. Durch Zerkleinern des Serpentins und Schlemmen des (iutes können die Nephritfragmente am hesten ahgeschieden und untersucht werden. Eine solche Struktur findet sich nur bei diesem Serpentin, auch nur in der Nähe seiner Rutschllïchen: einige cm davon entfernt lässt sich üherbaupt lieine Xephritsubstanz mehr nachweisen. C'hrysutiliderchen suwie 'Tr ï merchen 
von feinfasrigem Nephrit, die oft nur $0,03 \mathrm{~mm}$ mächtig sind, durchsetzen den Serpentin nach allen Richtungen, letætere finden sich aber ehenfalls nur in der Nähe der Rutschflächen. Ähnliches beobachtete II. Traube im Serpentin von Jordansmühl (N. Jahrb. für Mineral, Beil, Band III, 1884, S. 419). Ausser den Nephriteinlagerungen enthält der Serpentin noch $2-3 \mathrm{~cm}$ grosse viereckige Einschlüsse einer gänzlich verwitterten schwarzgrünen Substanz, deren mikroskopische Eigenschaften auf einen rhombischen Pyroxen deuten. Magnetit ist nicht so reichlich wie in den vorigen Serpentinen vorhanden und tritt in Krystallform und in feinen Dendriten auf. Die Struktur dieses Serpentinbelegstïckes ist lieine ausgesprochen maschige, vielmehr ein Fil\% von feineren und gröheren Serpentinfasern mit gelegentlichen Andeutungen der Olivin-Form. Es erklärt sich dies aus der Thatsache, dass der Serpentin sowohl durch Dynamowie durch Contactmetamorphose stark verindert wurde. Nach v. Hochstetters Angaben bilden Thonschiefer, Kalkepidotschiefer und ähnliche Gesteine den C'ontact mit dem Serpentinzug. In diesem Serpentin U 2 kommt der Nephrit demnach in Knollenform, in breccienartiger Struktur und in feinen Äderchen vor.

\section{Krystalline Schiefer und Mineralien.}

Von Gangquarzen, die an ihrem zerfressenen zelligen Aussehen als solche kenntlich sind, liegen Nr. S 8 und T2 2 ror. Sie kommen als Gänge in den Thonschiefern (s. u.) vor. Calcit erfüllt ihre Hohlräume, auch findet sich mit dem Quarz etwas Biotit und einige Thonschieferstückchen.

Die drei Nephritgerölle von der D'Urville-Insel und der im Serpentin U2 anstehende Nephrit werden weiter unten unter $\mathrm{C}$ abgehandelt werden.

\section{Schichtige Gesteine.}

Die Nr. E 2 und $3^{a}, \mathrm{U} 4$ und 5 sind Epidosite, die Übergaing ein epidotisirte Thonschiefer und in Kalkepidotschiefer (U 8) aufweisen. Sie bestehen aus Quarz und einem pistaziengrünen Epidut, der in Schnüren die Gesteine durchsetzt, aber auch derb 
vorkommt. Im Mikroskop betrachtet hesitzt or cine solduralle Farbe. Die (Quarzkörner sint meist idiomorph uml als Dihexiëler ausgebildet. Ihnen ist der Epidot in Körnern zonal eingestrent oder er häult sich auch inmitten der nie das Prisma aulweisenden (quarzirystalle an. Letrtere sind durchschnittlich

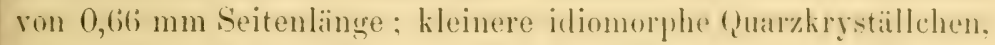
ebenfills nur als $\sim \mathrm{R}$ und $-\mathrm{R}$ ausgebildet, sind den grösseren ebenfalls zonal eingelagert. Kalkowsky herchreibt diese Erscheinung (Gneissformation des Eulengehirges, Leiprig 1878). Die kleineren Quarzdihexaëderchen messen oft $n u r .0 .04 \mathrm{~mm}$ in der grössten Diagonale, löschen unter sich ungleich und rom W'irt verschieden aus. ('hloritische sulstanzen hegleiten die Epilutkörnchen, ausserdem kommen noch skelettartige im durchfallenden Lichte opake, im auffallenden rothram gefärbte (iebilde hinzu, die wohl Hämatit sind. Einige scharfkantige Feldspatkörner wurden gelegentlich angetroffen.

Mit den schon von v. Hochstetter an der Okuri-Bay gefundenen grünlichen und gelblichen Kalkschiefern (s. S. 31) durlte der Kalkepidotschiefer U 8 identisch sein. Von demselben liegt ein granes etwas sichieferung reigendes finstgrosses Gerölle ror, das im Wesentlichen aus mittellïrnigem kompaktem von Bohrmuscheln durchlöchertem Kalkstein besteht. U. d. M. ergibt sich die übliche Struktur eines mittellörnigen Kallisteins, auf dessen undentlichen sichieferungstlïchen sich Epidotkörner einstellen. Thm sind noch scharfkantige Feldspattörner streifenartig eingestreut und ehenlalls solche von Ilmenit.

Die Nr. R 1-3, U 3, E 6 und 8 stellen Gra uwacken und Conglomerate vor, unter denen sich auch Porphyroide befinden mögen. (Hne eingehende [ntersuchung und gründliches Stulium des ganzen Reviers lässt sich diese Fange nicht entscheiden. Es sind gelbbraune, sowie hell- mol dunkelgrüne. teils massige, teils dünngeschieferte feste, in Allgemeinen feinkürnige (iesteine, in denen his zu 1/z cm grosso (quar\%- und Fehlspatfragmente nehen einigen Pyritkörnern aingehettet sind. Sie werden durch ein feinkrystallinisches Bindemittel verkittet. U. d. M. lösen sich die Gesteine in der Hauptsache zu einer 
Grundsubstanz von Quarz- und Feldspatliörnchen auf, welche mehr oder weniger dominiren kann. Grössere Kömer liegen, wie die Einsprenglinge in den Eruptivgesteinen, in dieser Hauptmasse. Hiervon sind zu nennen Quarzfragmente, die manchmal kaulquappenförmig ausgezogen und gestreckt sind, ferner zertrümmerte, meist trübe doch anch klare Feldspäte und grusartig verstreuter Augit, so dass durch diese Struktur das Bild eines Porphyroids entstehen kann. Die geschieferten Varietäten zeigen auch manchmal eine ähnliche teilweise kataklastische Struktur. Von accessorischen Gemengteilen der Grundsubstanz, die aber auch ganz fehlen kann, sind zu nennen: ein grünlichgeller schwach pleochroitischer Epidot, Chlorit, grünlicher Augit und grünliche stark trichroitische Hornblende, Biotit, einige abgerundete Zirkonkrystalle und Rutilkörnchen, Hagneteisen und endlich Pyrit, der sowohl in Krystallform wie in Körnern sich findet. E 8 enthiilt ausserdem noch Fragmente eines Eruptivgesteins, dessen porphyrische trübe (idiomorphe) Feldspatleisten in einer völlig zersetzten ebenfalls trüben Grundmasse liegen, sodass eine Bestimmung des ursprünglichen Gesteins unmöglich ist.

Von der Familie der Thongesteine wurden die $\mathrm{Nr}$. U 6. 9 ; T 1. 3; S 1-6. und 10 : E $3^{\text {b }}$. 4. 5. 7. 9 gesammelt. Es entstand zunächst die Frage, ob wohl Phyllite darunter sind. Fossilien fehlen gänzlich; v. Hochstetter gibt ihnen ein mesozoisches Alter; der typische seidenglänzende Glimmer auf den Schieferungsflïchen fehlt auch. Ich sehe sie daher für gewöhnliche sedimentäre Thonschief'er an.

Von ihnen ist U 6 ein hellgelblicher, leicht zerreiblicher, $\mathrm{Schieferthon,} \mathrm{der} \mathrm{etwas} \mathrm{geschichtet} \mathrm{ist.} \mathrm{In} \mathrm{dem} \mathrm{isotropen}$ trüben von einem Aluminiumhydrosilicat gebildeten Untergrund liegen scharfkantige Quarz- und Feldspatkörner nebst wenigen Glimmerblättchen.

Die übrigen 16 Gesteinsnummern bestehen aus gelben, schwarzgrünen oder hellgrauen $\mathrm{T} h \mathrm{n} \mathrm{sch}$ iefern, welche meist recht fest sind. Sie sind dünn geschiefert, zeigen Einlagerungen von Kalkspatkörnern und Schnüren (S 1) und hïufig Rutschflïchen. Ein mehr mergeliger Charakter ist einzelnen eigen, auch 
gewahrt man oft makroskopisch, wie auch unter dem Mikinshop. eine Failtelung. E5 ist ein hlutroter his haunroter Thonschiefor. in welchem einige schmale grïngelïrbte lagen bemerkbar sind. Das mikroskopische Bild ist bei Allen das gleiche. In einer feinkörnigen, je nach der lärloung des 'Thonschiefers gefirbten, isotropen Sulstanz liegen unregelmässige seharflintige

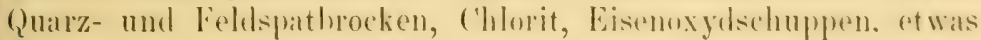
Magnetit und Schwefelkies. Kohlige Substanzen sind ihnen eingelagert, Quarzadem und Calcitschnüre durchziehen sie.

$\mathrm{Nr}$. U 7 ist eine Sammlung von Strandgeschieben von der Ostseite der D' Lirville-Insel, und zwar von dem auch auf der Karte vermerkten „alten Maori-I)orfe." L'nter ihnen sind (ieröle von Quarz und von rotem Jaspis, dann ein schwarzes völlig dichtes Geschiehe von nieriger Form, das die llärte $6^{1 / 2}$ hesitzt. Es erwies sich als eine feinsplitterige matte Adinole, die schwierig an der lichtflamme zu graulichem Email unter deutlicher Natriumreaktion schmilzt. Das sp. Gew. ist 2,74. L. d. M. sieht man in einem äusserst feinkörnigen undurchdringlichen Lntergrund echige Fragmente von (Yuarz und Feldspat netren einigen Leisten des letzteren Minerals liegen. Das schwarzfärbende Medium besteht ans Magnetit und einer hituminösen Substanz, die dem Gestein in Körnern und Schnüren eingelagert ist. Ferner wurden in dieser nur aus Strandgeröllen bestehenden Kollektion U 7 zwei Nephritgerölle, ein grïnes und ein rotes und in Kollektion $s 7^{\text {a }}$ ein weiteres grünes Geschiebe dieses Minerals gefunden, im Ganzen alsudrei (Xephrit I, II und III siehe S. 47 ).

U 10 ist ein aus Quarzkörnern, Magnetit und Chromit bestehender Meeressand. 
C.

\section{Die Nephrite der l'V'Urville- Ind der Stephens-Insel, derrunter Nephlrit inI Muttergestein (Serpentin U 2) von der D'Urville-Insel.}

Als Literatur, soweit sie neuseeländische Vorkommnisse betrilft und ausser der allgemeinen im folgenden Text aufgeführten, ist zu nemnen :

1. F. v. Hochstetter, Über das Vorkommen und die verschiedenen Abarten von neuseeländlischem Nephrit. (Sitz.-Ber. d. kais. Akad. d. Wissensch. Wien 1864. XXXXIX. S. 466-4S0).

2. A. Kenngott, Über Nephrit aus Neu-Seeland (Neues Jahrb. für Mineral. 1871. S. 293-295).

3. Fr. Berwerth, Über Nephrit aus Neu-Seeland (Sitz-Ber. d. kais. Akad. d. Wissensch. Wien 1879. LXXX. S. 102-118).

4. L. Duparc und L. Mrazek, Sur la Compositiou chimique de la Néphrite de la Nouvelle Zélande (Arch. Sciences phys. et nat. Genève XXVII, 1892. S. 115-121).

5. F. R. Chapman, On the Working of Greenstone or Nephrite by the Maoris (Transactions New Zealand Institute. XXI, 1891. S. $479-539)$.

6. II. Fischer, Nephrit und Jadeit. Stuttgart 1580.

Die zu besprechenden Nephrite sind

1) Strandgerölle und

2) dem Serpentin der D'Urville eingewachsene Knollen, wie folgt:

Zu 1) Nephrit I ein grïnes Strandgerölle von der D'Urville-Insel, am Jlaori-Dorfe gefunden;

Nephrit II ein rotes Strandgerölle von der L'Urville-Insel, am Maori-Dorfe gefunden;

Nephrit III ein grünes Strandgerölle von der nordwestlichen Bucht der Stephens-Insel;

Zu 2) Nephrit IV hellgrüne Knnollen im Serpentin (U2) von der D'Urvill e-Insel.

Die mit den Nephriten vorkommonden Gesteine sind unter 13 beschrieben worden (vergl. bes. Serpentin U2 S. 37). 


\section{Allgemeines über neuseeländischen Nephrit.}

Seit Joh. Reinh. Forster als naturwissenschaftlicher Benleiter C'ook's auf dessen zweiter Entrlerkungsteise unweit des Long Island in dem Queen Charlotte Sund der Cook-Strasse anstehenden Nephrit (talcum nephriticum) gefunden hatte und zwar nach seiner Angabe ,ganglörmig in einem grïnen, auch granen, blätrigen talkartigen (iestein" (J. R. Forster. Reise um die Welt, Berlin 1783, I, pag. 9), ist dieses Mineral nicht wieder anstehend auf Xen-seeland gefunden worrten, wenigstens ist hierüber nichts Sicheres bekinnt geworden.

Allerdings ist auf der 'Geological Sketch Map of New 'Zealand' von James Hector. Wellington 1873 an der Westliüste der Südinsel zwischen der Big-Bay und dem Cascade Pt eingezeichnet: 'Hornhlende shists with large veins of Jade.' Dieser Punkt liegt unter $44^{\circ} 5^{\prime}$ südl. Br. und $168^{0} 15^{\circ}$ östl. Lainge v, Greenwich. In der Literatur findet sich aber keine Beschreibung dieses Vorkommnisses, über das ich auch ron Sir James Hector auf wiederholte briefliche Anfrage nichts erfahren konnte. v. Il ochstetter (Lit. Nr. 1) kennt aus eigener Anschaunng keinen der vielen liundorte an der W'estküste der Südinsel, wo der Nephrit a uf sekundärer Lagerstäte vorkommt. Nach seinen Mitteilungen liegt der eine Fundpunkt im Bette des Brunner Flusses, ein zweiter ,am See Punamu (sive Wakatipu)" in der Prorinz Otago. Bezïglich des dritten Fundortes in der Anita-Bay des Milford Sound sagt Hector (Provincial Ciovernment Gazette of Otago Nr.460, 1863, pag. 3). dass er wohl strandgerölle aber keinen anstehenden Nephrit gefunden habe, doch scheine derselhe am Kontalit von Serpentin mit 'lelsite' vorzukommen. Fluss- und Straudgerölle werden ron letztgenanntem lem südlichsten Fundurt in nördlicher Richtung entlang der ganzen Westküste his zum Liap Foulwind gefunden, 1. h. auf einer $600 \mathrm{~km}$ langen strecke. v. Hochstetter (s. o. S. 31) sammelte ein abgerolltes Stück an der Okuri-Bay (s. Tafel III). Die Fundorte der von Scha u insland nördlich daron und ebenfills am strande aufgelesenen drei Nephritgerölle liesen wie die (1kuri-Bay im Bereich cines mächtigen Serpentinzuges (vergl. S. 30). Ein- 
geschlossen im Serpentin, welcher diesem Zuge entstammt, fanden sich die Nephritknollen; sie sollen zuletzt beschriehen werden.

Da die drei Nephrite I-III Strandgerölle sind, so entstand zunichst die Frage, ob sie wohl einheimischen Ursprungs seien. 1)ie (iesteine der D'Crville- und Stephens-Insel sind die gleichen, welche die bisher bekannten weiter südlich in den Southern Alps gelegenen alluvialen Nephritfundstätten begleiten und zwar sind dies Serpentin, Iornblendeschiefer und metamorphe Thonschiefer, sowie Eruptirgesteine. Ferner zeigen die drei Gerölle völlige Rundung und gehören zu den von den Maoris besonders geschätzten Abarten 'Kahurangi' oder 'inanga' (s. Lit. 1), aus denen sie ihre Ohrgehänge und andere Schmuckgegenstände herstellten. Auch hat Nephrit II eine $2 \mathrm{~mm}$ starke carminrote Verwitterungsinde, die nur in langen geologischen Zeiträumen entstanden sein kann. Bei der Analyse des Nephritgerölles I ergab sich ferner ein aus eingesprengten Kuplererzen herrührender Kupfergehalt von $0,17^{\circ} / 0$; die Nephritknollen im Serpentin zeigen ebenfalls einen kleinen Kupfergehalt, der seine Crsache in Malachitanflügen hat. Die drei Nephritfunde vom Strande und derjenige $\mathrm{Hochstetters}$ an der Okuri-Bay liegen in einer geraden Linie und im Bereich des Serpentinzuges, in dessen Giestein ich den anstehenden Nephrit (Nr. IV) fand. Ein fremder I'rsprung der drei Nephritgerölle scheint mir demnach ausgeschlossen zu sein.

Sehen wir uns nun auf der Erde um, mit welchen Arten von (iesteinen der Nephrit auftritt, so ergibt sich, dass H. Traube (s. S.38) in Schlesien den Nephrit im Serpentin und an dessen Kontakt mit Granulit fand, ferner bei Reichenstein in Schlesien (Neues Jahrb. f. Min. 1887, II, S 276) in einem Diopsidgestein und im Serpentin. In Central-Asien kommt der Nephrit im Gneis, Ilornblende- und Glimmerschiefer und im Serpentin vor, dann auch am Kontakt von augitsyenitischen und granitischen Gesteinen mit Diabasen und Gabbros. Vergleiche hierüber: K. J. Bogdanowitsch (Referat, N. Jahrb. f. Min. 1894, II, S. 24), Stoliczka (Quart. Journal Geolog. Soc. XXX, 187t, S. 5(i8), Martin (Comptes Rendues 1891, Bd. 112, S. 1153), v. Richth ofen (Verh. d. Ges. für Erdkunde 1874, Nr. 6 u. 7, 
S. 183). Fs interessirte nun auch das Muttergestein des Xephrits in Alaska kennen zu lernen. Eine Anfrage an die Herren Clarke und Merrill, die Verfasser von On Nephrite and Jadeite' (Proceedings Lnited states National Musem 1888. S. 115-130) wurle am 5. Hairz 1!)1 von Herru dieorge P. Merrill. Head Curator des genannten Museums, folgendermassen beantwortet: "The character of the mother rock of the Alaskan Nephrite is not satisfactorily known. Lieutenant Stoney sent first samples of serpentine and quartzite on the supposition that they were Nephrite and I have thought it probable, that the first named was the rock associated with the Nephrite, but have no proof of this. The Nephrite comes from the Jade Mts. 150 miles north of Korwak River, Alaska.'

Hiernach ergibt sich iiberall eine Analogie unter den Giesteinen, welche den Nephrit beherbergen und die ja auf' der I)'Trville- und der Stephens-Insel den citirten ganz ähnliche sint.

Ich habe nun die einschligige Literatur nach allen Nephritfundstätten Neu-Seelands durchsucht und fand füir anstehenden Nephrit nur den einen Fund sicher verbiirgt, den J. R. Forster (s. S. 43) gemacht hat. Die Belegstïcke sind aber verschwunden, wie mir Herr L. Fletcher vom British Museum mitteilt, sodass eine Kontrulle nicht ansgeült werden kann. Die auf $\$ .43$ erwähnten Vermutungen Hectors beziehen sich nicht auf Nephrit im mineralogischen Sinne, sondern, wie sich klin ergeben hat, auf Tangiwai : einen P'sendonephrit! Der Misssionär J. W. Stack (Lit. 5 S. 512-514) betont besonders, dass seines Wissens Nephrit noch nicht anstehend in Neu-Seeland gefunden sei. Diese Angabe machte der seit 20 Jahren unter den Maoris lebende (ieistliche im Jahre lisil, wohat ich diewicht legen möchte. Hein Fund im Serpentin der D'Urville-Insel wäre demnach der erste sichere und wisschischaftlich untersuchte Nephrit im Muttergestein auf Nen-Seeland. Dies bestitigt ller Il enry A. Gordon, bis vor kurzem (hief Inspecting Engineer of the Mines Jepartement of New Zealand, der mir am 1. April 1901 mittheilt, dass alle Expeditionen, welche zur Auffindung anstehenden Nephrits von der Berghehörle

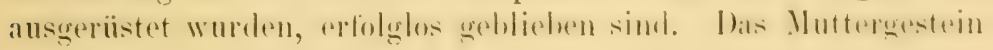


des Tephrits ist mach seinen Mittheilungen hislang in NeuSeeland noch nicht gefunden worden.

Als Fluss- und Strandgerölle wird der Nephrit an folgenden P'unkten Neu-Seelands gefunden, die alle an der mir zum Teil persönlich bekannten Westküste der Südinsel liegen:

1. im Bette des Greenstone Creek, einem Nebenfluss des Teremaku (sive Taramaku);

2. an der Mündung und im Bett des Teremaku-Flusses (Hohonu der Maoris);

3. an der Mündung und im oberen Laul des A rahuraFlusses, der circa $15 \mathrm{~km}$ südlich vom vorigen Flusse sich ins Meer ergiesst. Man darf ihn nicht mit dem A haura Filusse, einem Nebenfluss des Grey $\mathrm{R}$ iver verwechseln;

4. ain Meeresstrande zwischen den sub 2. und 3. genannten Flüssen, d.h. ungefähr zwischen den Städten Hokitika und Greymouth.

Der von 2., 3. und 4. eingeschlossene Berirk ist am reichsten an edlem Nephrit und führt bei den Maoris den Namen Te Waipumanu im engeren sinne. Wai hedentet Wasser und pumanu Grünstein (Nephrit).

5. In der Umgegend der $\mathrm{B}$ a ra- $\mathrm{B}$ a y, $44^{\circ} 10^{\prime}$ südl. Br. und $186^{\circ} 20^{\prime}$ östl. Länge gelegen;

6. im Hope-Flusse, der $10 \mathrm{~km}$ nördlich von der BaraB a y in's Meer mündet;

7. im Bett des Wainihini-Flusses.

8. im Wildbach Piopiotahi. der in den weiter südlich gelegenen Milford-Sound mündet. In ihm wird wie

9. am Strande der Anita-Bay. welche unweit der Einfahrt zum Milford Sound sich befindet, nur der Tangiwai (Kokottangiwai der Maoris) gefunden, ein Pseudonephrit!

10. an der Okuri-Bay des Current-Basin (v. Hochstetter);

11. auf der I' 'Urville-Insel an einem Punkte gegenüber den Rangitoto-Inseln (Scha u insland);

12. auf der Stephens-Insel an der nordwestlichen Bucht (derselbe).

Angeblich wurde der Nephrit noch an Lake Whakatipu oder Wrakatapu gefunden. Nach neueren Forschungen 


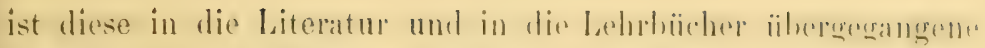
Angabe irrig. Whakatipu war ein Synonym der Maris fïir den unter 8. und 9. genamnten Milford Sound. Am Ufer des gleichnamigen Binnensees Wakatipu in dee Provinz () tatg" ist kein Nephrit gefunden worden. Die Maoris, welche den Nephrit quer durch die Alpen nach ihren an der Ostküste gelegenen Werkstätten trugen, benutzten den lür sie gänstig ge-

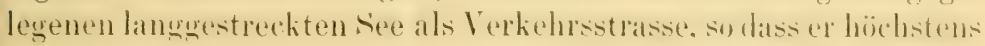
als Etappendepot, nicht aber als eigentlicher Fundort in Betracht kommt. Als sie die Gegend um den Milford Sound im Jahre 1849 abtraten, bezeichneten ihre Lliuptlinge sie in den Verkaufsiontrakten mit "Whakatipu". ein Xame, leer seither nur noch für den Binnensee gilt. Hierdurch entstand nach Chapman's Ansicht (Lit. Nr.5 S. 524) der Irrtum. Statt des Fundortes "um Lake $\mathbb{W}$ hakatipu" muss es in Zukunft heissen: a m Nilford-Sound (Anita-Bay und P'iopiotahi-Bach) findet sich der 'Tangiwai, ein Psendonephrit, in Strand- und Flussgeröllen. Ein weiterer unsicherer liundort ist die Jackson-Bay, welche einige Autoren als gleichbedeutend mit II il ford-sio und allselsen, obwohl letzterer $90 \mathrm{~km}$ südlicher liegt.

Wir gehen nummehr zur Beschreibung der neuen Nephritfunde über, darunter desjenigen im Serpentin.

\section{A) Die Nephritgerölle ( $\mathrm{Nr}$. I, II und III).}

Die Farbe der Stücke ist etwas verschieden. Nephrit I ist auf der glatten (oberlliche, welche stets dunkler ist als die Bruchfläche, dunkelgrasgrün (Radde $1+e-f$ ), Vephrit III sriagrün in's. blaugrüne (Radde $15 e-1)$. Auf dem Bruche sind bei beiden Schattirungen von neutralgrau $(31 e-f)$ mit lichteren grïnen Partien $(15 r-s)$ zu erkennen. I)ie Rinde des Nephrits II zeigt eine carminrothe Farbe, flammenartig ron dunkleren Partien

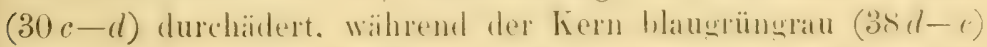
ist. An den zähen Nephriten lassen sich gewisse Richtungen geringeren Zusimmenhalts hemerten, die sich schon äuscrlich durch die wolkige Zeichnong und eine in derselben Richtung

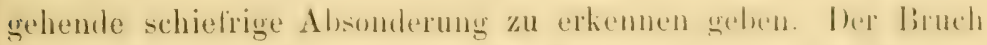
ist splittrig und wie bestiubt, die llïrte $5^{3 / 4}-6^{1}, 4$, stellenw eise 
etwas höher. Splitter schmelzen vor dem Löthrohr schwierig an den Kanten zu einem emailartigen Glase.

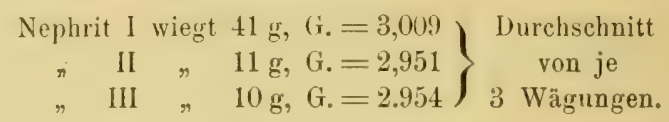

I) uparc und Mrazek (Lit. 4) führen auf Grund einiger von ihnen gemachten Analysen aus, dass bei den von ihnen untersuchten neuseelïndischen Nephriten der "Gl ühverlust" sich konstant zwischen 2,5-2,6\% bewege. Wahrscheinlich meinen die genannten Autoren mit "Glühverlust" die bei Rothglut des Platintiegels entstandene Gewichtsdifferenz. B erw e r th (Lit. 3) hemerkt, dass er hei neuseeläudischen Nephritproben, die er hei $120^{\circ}$ trocknete, $2,61 \%$ und bei Wiederlsolung $2,96 \%$ Verlust erhielt. Andere Analytiker (I) an a 's System of Mineralogy, 6. Aufl., S. 394, und Carl Hintze, Handbuch der Mineralugie, Leipzig 1896, s. 1250 ff.) geben $0,68-3,75 \%$ als (ilühverlust (igneous loss) hei Nephriten verschiedener Provenienz an. I) ie Resultate meiner Wasserbestimmungen, beide von sehr feinem Pulver des Nephrit I, sind die folgenden :

a) $0,5183 \mathrm{~g}$ verlor in 6 Stunden bei $120^{\circ}$ getrocknet $0,0046 \mathrm{~g}=0,88 \%$

b) $0,6264 \mathrm{~g} \quad, \quad \Rightarrow \quad$ " $\quad$ " $\quad, 0,0059 \mathrm{~g}=0,94$,

Bei weiterem sehr vorsichtigem Erhitzen auf schwache Rothglut his yur Konstanz ergab die ursprüngliche Substanz:

a) einen Gesammtglühverlust von $0,0125 \mathrm{~g}=2,41 \%$

b) $\pi \quad \pi 0,0143 \mathrm{~g}=2,28$,

In der folgenden Tabelle gibt Reihe 1 und 2 die Resultate meiner Analysen des Nephrits I wieder, Reihe 3 die U'mrechnung auf 100 unter Vernachliissigung von $\mathrm{Al}_{2} \mathrm{O}_{3}, \mathrm{H}_{2} \mathrm{O}$ und $\mathrm{Cu}$, während Liolumne 4 den Durchschnitt ron 4 Analysen neuseeländischer Nephrite der Herren I) upare und Mrazek (Lit. 4) aufführt. Zum Gang der Analyse ist zu bemerken: der Nephrit I wurde zwischen 2 Stahlplatten verrieben und im Achatmörser pulverisirt. Dieser wird von grobem Nephritpulver angegriffen. Nachdem die Stahlflitterchen des Hammers u. s. w. durch den Magneten entfernt waren, wurde $\mathrm{Si}_{2}$ aul gewöhnlichem Wege, Calcium mit Ammoniumoxalat, Magnesium als Phosphat gefällt. Der nur als $\mathrm{FeO}$ anwesende Eisengehalt wurde mit der 'Thonerde als $\mathrm{Fe}_{2} \mathrm{O}_{3}$ 


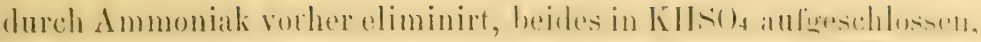

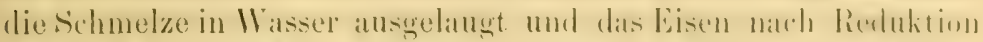

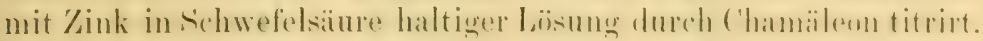

\begin{tabular}{|c|c|c|c|c|c|c|}
\hline & & & 1. & 2. & 3. & 4. \\
\hline $\mathrm{SiO}_{2}$. & . . & . & 55,59 & 55,82 & 57,96 & 55,99 \\
\hline $\mathrm{Al}_{2} \mathrm{O}_{3}$. & . . & . & 1,43 & - & - & - \\
\hline $\mathrm{FeO}$. & . . & . & 6,15 & 5,90 & 6,40 & 5,20 \\
\hline $\mathrm{CaO}$. & . . & . & 12,93 & - & 13,49 & 14,18 \\
\hline IIfO . & . . & . & 21,24 & - & 22,15 & 21,67 \\
\hline $\mathrm{H}_{2} \mathrm{O}$. &. & . & $2,35^{*}$ & - & - & 2,56 \\
\hline $\mathrm{Cu}$. . & . . & . & 0,17 & - & - & $0,42 \mathrm{Cr}_{2} \mathrm{O}_{3}$ \\
\hline & Sum & & 99,86 & - & 100.00 & 100,02 \\
\hline
\end{tabular}

*) Durchschnitt obiger 2 Bestimmungen.

Alkalien wurden nicht bestimmt. Das Kupfer wurde kolorimetrisch in ammoniakalischer Lösung ermittelt. In der Phosphorsalzperle zeigt sich schwache C'hromfirithung, während Mangan durch die bekannte Schmelze nachgewiesen wurde.

Die Analyse zeigt, dass eine bestimmte chemische Formel sich für diesen Nephrit nicht aufstellen liisst. Durch die iibliche Berechnung ergibt sich folgendes Molecular-Verhältnis:

$$
\begin{gathered}
960 \mathrm{SiO}_{2}: 549 \mathrm{MgO}_{\mathrm{gO}}+89 \mathrm{FeO}: 240 \mathrm{CaO} \text { oder } \\
4 \mathrm{SiO}_{2}: 22_{3}(\mathrm{MgO}+\mathrm{Fe}): 1 \mathrm{CaO} \text { ? }
\end{gathered}
$$

Dagegen ist Aktinolit wie folgt:

$$
\text { 4 } \mathrm{SiO}_{2}: 3(\mathrm{Jg}, \mathrm{Fe}) 0: 1 \mathrm{CaO}
$$

zusammengesetzt. I)iese kleine Diflerenz lässt vermuten. diss eine geringe Nenge von Verunreinigungen vorhanden ist.

Der mikroskupische Befumb dieser drei Cephritgerille ist im Allgemeinen der gleiche, sie werden deshalh gremeinsim hesprohen:

Bei gewöhnlichem Licht zeigen sich in den u.d. If. farb-

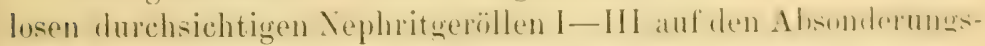
flächen Anhäufungen von Epidotkörnchen, deren Anwesen-

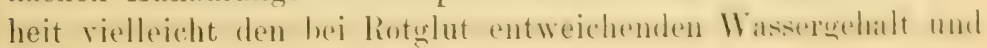


die hei der Analysenberechnung entstandene Differenz erklärt. In allen Schliffen dieser 3 Nephrite fand sich ein farbloser Granat in Körnern und in länglichen Trümmeranhäufungen. Er charakterisirt diese Nephrite geradezu, da meines Wrissens (iranat noch nicht als (iemengteil des Nephrits nachgewiesen worden ist. Ferner treten $Z_{0}$ is it in gerlrungenen Säulchen bei 250 facher Vergrösserung aus dem Nephritfil\% hervor. B io tit und Magnetit sind untergeordnet vorhanden. Pyroxensä ulch en mit einer Auslöschungsschiefe von $36^{0}$ wurden heobachtet, doch ist ihr Vorkommen zu spärlich, um weitere Schlüsse daraus ziehen zu können. Eisenhydroxyd-Infiltrationen sind nicht selten. Aus dem feinen Nephritfilz treten etwas pleochroitische und auf gewisse Erstreckung parallel gelagerte Aktinolitreste mit markantem Relief hervor, deren Enden eine deutliche Auffiserung und einen weiteren allmählichen Übergang vom Krystallbruchstück zur Nephritfaser zeigen; ihre stellenweis parallele Orientirung, rerbunlen mit gleichem optischen Verhalten, liisst schliessen, dass diese Fragmente ursprünglich einen zusammenhängenden Aktinolit Krystall bildeten, der dann durch dynamometamorphische Processe zertrümmert, zerfasert und in den Nephritfilz umgewandelt wurde. Auf Tafel IV sieht man in der Abbildung 5 rings um drei Spaltungsstiicke eines Aktinolit-Kirystalls kleinere, ebenfalls noch ziemlich unveränderte Partien des gleichen Minerals wie Trabanten liegen. Die Auffaserung ist besonders an den letzteren $z u$ sehen und ebenso der weitere Ühergang in den auf der Photographie weissen Nephrittilz. Beim Studium der Mikrostrulitur lassen sich drei Stufen der Wirkung dynamischer Vorgänge deutlich beobachten:

1. die eben erwähnte Zerreissung der Krystalle.

2. Auswalzung dieser in gröbere Nephritfisern (s. unten),

3. das Endprodult, nïmlich die den eigentlichen Filz bildenden feinsten Nephritfïserchen (s. unten).

Bei 50 facher Vergrösserung und unter gekreuzten Nicols sieht man den aus diumsten und feinsten Nephritliserchen (3.) hestehenden verworrenen Filz sich in einzelne mehr oder minder volliommene hüschel- und hündellörmige Aggreggate auflösen. Die oft von einem gemeinsamen Mittelpunkt ausstrahlenden 


\section{$-51-$}

Büschel durchkienzen sich, erreifen zahnartig in cinander mul vereinigen sich dann wieder zu etwas gröberen l'asern, die bald grerade, bahd wellig gehogen orler atuch gekniclit und gekrïmmt sind, so dass man ihre relativ geringe duslïschungsschiefe selten messen kamn. In diesem verworrenen Grundfilz treten, wenn der sichlill parallel zu den oben rrwähnten Alsonderungsllïchen der Nephritknollen (s. S. 47) geführt wurde, gröbere lang ausgezogene, parallel orientirte Nephritfasern (2.) auf, die auch wellig gebogen sind, alver im Gegensatz zu den feinsten Fäserchen nicht hüschelfürmig struirt sind. Sie rulen durch ihre l'arallellagerung in schlill eine scheinhare Schieferung hervor und sind parallel der krystallographischen Verticalate ansgewalyt. Eine einheitliche Auslöschung ist ihnen eigen, deren schiefe nie diejenige des Amphihols ïhersteigt. Als grösster Winkel wurle $22{ }^{0}$ gemessen. Ist der Schliff dagegen senkrecht zu den genaminten schiefrigen Alisonderungsflichen geschnitten worden, so verschwinden die gröberen Fasem, von denen dann nur Querschnitte gesehen werden können. Lnter diesen befindet sich ein śchnitt senkrecht zu einer der optischen Axen, deren Dispersion mit grosser Wahrscheinlichkeit als $\varrho<v$ beobachtet wurde.

\section{B) Nephrit IV, im Muttergestein von der D'U r'ville-Insel.}

Die Beschreibung des Serpentins U 2 findet sich auf S. 37. In ihm kommt der Nephrit in dreierlei Form vor und zwar

I. als rundliche, von Serpentinsubstanz um- und durchwachsene Knollen,

II. in breccienartigen Fragmenten und als feine Äderchen.

\section{Die Nephritknollen im Serpentin.}

Sie werden ron Serpentin umhüllt und der grünlich weisse Kern oflenhart sich erst durch Zerschlagen oder durch Abkritzen der Rinde. Der grösste dieser Nephritlerne hatte cinen I)urchmesser von $2 . \mathrm{cm}$ und wog $5 \mathrm{~g}$, doch sind noch kleinere bis $204 \mathrm{~mm}$ burchmesser vorhanden. Das spez. (iew. dieses Vephrits, dem immer noch etwas Serpentin beigemengt war, hetrïgt 2.95, die llïrte und das Jöthrohrverhalten sind wie bei den Nephrit- 
geröllen (S. 47). Die Farbe ist heller wie bei jenen und hellgrasgrün (Radde $15 t-u$ ) mit einigen satteren'Streifen $(15 n-0)$. Es sei hierbei an die Beobachtung H. Traube's (l.c.) erinnert, dass die dem Jordansmühler Serpentin eingelagerten Nephritknollen eine hellere Farbe als diejenigen aus dem GranulitKontakt besitzen. Vor dem Lïthrohr brennt sich dieser Nephrit gelblich-weiss und bleibt dann auch so.

Wenn nun auch an der Nephritnatur dieser Knollen kein Zweifel sein konnte, zumal die gleich zu hesprechende Mikrostruktur das Bild eines Nephrits ebenfalls bot, so war es doch wünschenswerth, die chemische Zusammensetzung kennen zu lernen. Zu diesem Zweck wurden möglichst reine Nephritstückchen unter der Lupe ausqesucht und damm pulverisirt. Das erhaltene Probegut wurde mit conc. II'I mehrere Male gekocht, um den Serpentin zu zerlegen. Die abgeschiedene Kieselsäure wurle darauf in $15 \%$ iger Kalilange gelöst, machdem ich mich üherzengt hatte. dass eine Lösung von Alkalicarbonat nicht zum Ziel führt. Die nicht angegriffene Nephritsulstanz wurde dann auf dem S. 48 angegebenen Wege analysirt und ergab die in Reihe I und II aufgeführten Resultate. Aus Reihe III ist der Jurchschnitt dieser beiden von mir angefertigten Analysen ersichtlich. Kolumne IV erwilit endlich die I'mrechnung des Durchschnitts auf 100 unter Vernachlïssigung des (ilïhverlustes und der Thonerde und $\mathrm{V}$ die theoretische Zusammensetzung des Aktinolits.

\begin{tabular}{|c|c|c|c|c|c|}
\hline & 1. & II. & III. & IV. & v. \\
\hline $\mathrm{SiO}_{2} \ldots$ & 52,38 & 53,15 & 52,77 & 56,32 & 57,85 \\
\hline MgO & 20,74 & 21,60 & 21,17 & 22,60 & 28,74 \\
\hline $\mathrm{CaO}$... & 15,73 & 15,05 & 15,39 & 16,43 & 13,41 \\
\hline $\mathrm{FeO}$ & 4,36 & 4,36 & 4,36 & 4,65 & - \\
\hline $\mathrm{Al}_{3} \mathrm{O}_{3} \ldots$ & 2,07 & 1,69 & 1,88 & - & - \\
\hline $\begin{array}{l}\text { Glühverl.b.schwacher } \\
\text { Rotglut d. Tiegels }\end{array}$ & 2,77 & 2,77 & 2,77 & - & - \\
\hline Summa & 98,05 & 98,62 & $98 ; 34$ & 100,00 & 100,00 \\
\hline
\end{tabular}

*) Durchschnitt zweier Bestimmungen. 
Die erhehliehen Dillerenzen der einzehen Positionen in Ruihe I und II sind dureh die Verschiedenheit der Probesubstanzen erkliarlich. Alkalien wurden nicht hestimmt. C'hrom fehlt, forh wurden spuren ron Kupfer auch diesmal natchgewiesen; Mangan ist ebentalls anwesend.

Auch für diesen Nephrit kann eine bestimmte chemische Formel nicht aufuestellt werden. Das Molekularverhältnis ist folgendes:

$$
932 \mathrm{SiO}: 560 \mathrm{MgO}+65 \mathrm{FeO}: 293 \mathrm{CaO}
$$

oder ungefähr:

$$
3 \mathrm{SiO}_{2}: 2(\mathrm{Ng}, \mathrm{Fe}) \mathrm{O}: 1 \mathrm{CaO} .
$$

Dieses Verhïlnis deutet auf die gleichzeitige Anwesenheit ron Aktinolit und thonerlefreiem Augit, sodass dieser Nephrit

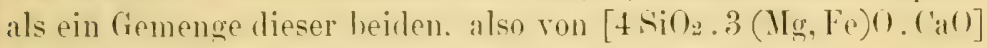
und $\left[2 \mathrm{Si} \mathrm{O}_{2} \cdot(\mathrm{Mg}, \mathrm{Fe}) \mathrm{O} \cdot \mathrm{CaO}\right]$ zu betrachten wäre.

Die mikroskopische Beobachtung bestätigt diese Annahme. denn dieser im Serpentin gefundene Nephrit ist im Gegensatz zu den hereits hesprochenen 3 Tephritgeröllen ein SekundiirNephrit oder Uralitnephrit.

Unter dem Mikroskop äussert sich die Tralitisirung des Angits durch die rerschieden hohe Auslïschung des Kerns und seiner etwas aufgefaserten End- und Randteile. die damn im Gegensaty zum Kern Pleochroismus vou farhlos his in's hellgrünliche aufweisen. Auf Tafel IV Abh. 4 ist eine IIikrophotographie wiedergegeben, die rersuchen soll, diese Erscheinung zu zeigen. Der Augitkern ist schwarz, die weissen, mit II hezeichneten Randund Endteile hestehen aus Hornhlende. Die Mikrostruktur dieser Knollen ähnelt sehr derjenigen der drei Nephritgerölle. nur fehlen die gröheren Fasem (2.) hier fast ganz. Der Filz, welcher aus feinsten Fäserchen besteht und ganz wie derjenige der (ierölle heschaffen ist, umschliesst auch noch unregelmässige Fragmente von Serpentin, welcher den Nephrit in feinen Ärlerchen durchsetzt. Es finden sich in diesem Nephrit Körnchen von Epidot, dann Magnetit und einige fast larblose, manchmal etwas pleochroitische A ugite, lie olt noch scharfe Begrenzung zeigen und stets undulöse Auslïschun£ besitzen. Ausserdem wurden noch dendritische Infiltrationen ron Eisenhydroxyd 
beobachtet. Der Uralit ist nicht selten und zwar besitzt der Augit dann einen mehr oder minder dicken Mantel von Hornbende. Uralitnephrite aus Asien beschrieben Beck und Muschketow (Verh. d. Kais, russ. mineral. Ges. XVIII, 1883, S. 38) und Arzruni (Zeitschrift für Ethnologie, Berlin 1883, S. 175).

\section{Nephrit in breccienartigen Fragmenten und als Äderchen im Serpentin.}

Ein Schliff von der Rutschfläche im Serpentin lässt eine kataklastische breccienartige Struktur der Nephriteinschlüsse erkennen (s. unter Serpentin U2 auf Seite 37), insofern letztere in scharfkantigen kleinen Fragmenten im Serpentin liegen, der sie umhüllt. Hier finden wir den Nephrit als einen äusserst feinlasrigen Filz ausgebildet, dem fremde Beimengungen söllig fehlen. Bemerkenswerth ist, dass in diesem Pripparat analog dem Jordansmühler Vorkomnis der Nephrit mit feinen, manchmal kaum 1/33 mm breiten Äderchen den Serpentin durchsetzt. Makroskopisch konnte dies nicht beobachtet werden.

\section{Resu m é.}

J)ie Lntersuchung der Nephritvorkomnisse hat gezeigt, dass Nephrit auf der D'Crrille- und der Stephens-Insel in liorm ron Strandgeröllen sich findet und ausserdem auf ersterer auch i m Serpentin, seinem Muttergestein, vorkommt. Während die Gerölle keine Uralitisirung zeigen, ist der im Serpentin auffundene Tephrit davon verschieden und ein Uralitnephrit. A us dem Gesagten ergibt sich, dass zwei verschiedene Nephrite an einem und demselben Orte vorkommen können und dass das bekannte Axiom von Arzruni (Zeitschr. für Ethnologie, Berlin 1883, s. 175) fïr diejenigen der D'Crville-Insel nicht zutrifft.

Eine weitere eingehende Erforschung des Serpentinzuges soll in Kürze von einigen auf der D'Urville-Insel wohnenden. Bekamnten des Herrn Prof. Schauinsland vorgenommen werden. Jabei wird vielleicht ein den Geröllen gleichkommender PrimärNephrit auch im Serpentin gefunden werden. 
D.

\section{Die Fossilien der C'hatham-Inselı und der I'Urville-Inselgr'uppe.}

\section{Die Chatham-Inseln.}

Die Fundpunkte sind:

1. vom Flowerpot-IIafen auf Pitt Island;

2. von Whakekauri, von Tioreors und beim Mt. Engst an der Nordküste der Hauptinsel;

3. aus den Red Blufts und aus den Kalken der Lagune.

Herr Geh. Reg.-Rat Prof. Dr. E. v. Martens in Berlin hat es ïbernommen, die vorliegenden stücke mit den recenten nenseeländischen Arten zu vergleichen, während Herr Prof. Dr. Gustar Steinmann-Freiburg i. B. die Bestimmung einiger Fossilien förderte. Hierfür erlaube ich mir genannten Herren meinen verbindlichsten I)ank aus\%usprechen. Ausserdem hahen die Herren Prof. Dr. O. Jaekel, Dr. M e issner, Dr. E. Philippi und Herr II ustedt, sämtlich in Berlin, mich durch Bestimmung einiger spezialititen unterstützt, wolür ich Ihnen dankbar bin.

\section{Von Fundort $1 \mathrm{kommen}$ :}

a) Waldheimia lenticularis Desh in Exemplaren von $4^{1 / 2} \mathrm{~cm}$ Breite und $6^{1 / 2} \mathrm{~cm}$ Höhe.

b) Eine auf Basalthonglomeraten und Kalksteinen sitzende Pectunculus-Art von $3^{1} / 2 \mathrm{~cm}$ Lainge und gleicher Breite, die mit P. lenticularis Tate verwandt ist. Herr v. Martens schreibt mir: „Ich habe keinen aufälligen Interschied \%wischen dem Ihrigen und P. laticustatus (2noy und Gaimard von Neu-Seeland bemerkt, die auch noch bei den Chatham-Inseln lebend vorkommt; die Rippen sind verhältnismässig etwas höher und weniger flach als beim lebenden."

c) Eine mit a) auf Kalksteinen und Tulfen vorkommende T'erebratula, deren Gerüst auf T'erebratula im engeren Sinne hinweist. Die grössten Exemplare messen $38 \mathrm{~mm}$ in der Breite, $48 \mathrm{~mm}$ vom Schnabel bis Stirnrand und sind $24 \mathrm{~mm}$ dick. Dats Schnabelloch ist gross und nach aussen 
gerichtet, die Schalen sind concentisch grob gefaltet und die stark gewölbte Ventralklappe greift mittelst übergebogener Falte über die kleine Klappe hinweg. Bei älteren Tieren zeigt sich am Stirnrand der Bauchklappe ein Sinus, dem ein schwacher Wulst der Dorsalklappe entspricht. Das Armgerïst ist kurz, besteht aus 2 absteigenden und zwei unter einem spitzen Winkel zusammenstossenden aufsteigenden Ästen. Der Cruralfortsatz endigt spitz.

d) Eine in Bratuneisenstein verwandelte Schale eines Pecten von $10 \mathrm{~cm}$ Breite und Höhe, die P. modestus Sow. von Australien und P. laticostatus (iray (Novae Zeelandiae Reeve) von Neu-Seeland ähnelt.

Von Fundort 2 und 3 kom men:

e) Ein Bruchstück einer ebenfalls in Brauneisenstein verwandelten Pectenschale von gleichen Dimensionen. Ilierzu passt keine lebende australische oder neuseeländische Art; von recenten Arten anderer Meere lässt sich nach gütiger Angabe des Hern v. Martens am besten Pecten tenuicostatus Mighels ( $=$ Clintonius Pay) damit vergleichen, die im Staate Rhode Island und bei Long Island im Staate New-York lebt, aber nicht in der Magellanstrasse, wie friber angegeben wurde, vorkommt.

1) Eie kleine dünnschalige Gry phaea, mit G. tarda Hutton verwandt, findet sich in einer Kalkbank des Steilufers bei Tioreors.

Von Fundort 4 (s. S. 29) kommen:

g) Die Kalksteine des Lake Huro, der Lagune und einzelne kalkig thonige Lagen der Red Bluffs sind mit Seeigelstacheln erfüllt, die nach gütiger Mitteilung des Herrn Dr. Meissner-Berlin zu einer mit idaris (Phyllacanthus??) verticillata Lam vesrandten Art gehören.

li) Einige Echiniden aus demselben IIorizont sind unbestimmbar; die schlecht erhaltenen Exemplare dürften wohl der Kreide angehören. 
i) In denselben Kalkentinden sich von Bryozoen: Spiropora verticillata Gif. Vincularia sp. cl. Goldfussi Rss, Lichenopora cf. reticulata, Desmepora cf. semicylindrica Röm oder rugosa d'Orb.Die Bryozoen sind nach Ansicht des Herrn ll ustedtBerlin wahrscheinlich senonen Alters.

\section{Fossilien der D'Urville-Gruppe.}

Am French-Pass wurde Monotis salinaria Schloth (s. S. 31) und anf der Höhe eines benachbarten Berges ein ron Herru Prof. E. Fraas-Stuttgart bestimmter fossiler Schädelrest von Z iphius indicus. v. Ben. gefunden, der aus Mesethmoideum und oberer Endigung des Maxillare besteht.

Am Schlusse meiner Arbeit angelangt, liegt mir die angenehme Pflicht ub, meinem hochverehrten Lehrer Herrn (ieh. Rew.Rat Prof. Dr. Nax Bauer für die mir reichlich und stets gewährte Lnterstützung und für viele liebenswürdige Ratschlïge auf das Beste zu danken.

\section{Berichtigungen.}

S. 37 Z. is von unten lies: von der D'Urville-Insel statt: an der D'Ur-ville-Insel.

S. 38 Z. : on unten lies: gånge in statt: gäng ein.

S. 50 Z. 6 von oben lies: Ferner tritt statt: Ferner treten.

S. $54 Z .16$ von oben lies: $0,03 \mathrm{~mm}$ statt: ${ }^{2} / 33 \mathrm{~mm}$. 


\section{Lebenslauf.}

Icb, Arthur Dieseldorff, bin evangelischer Konfession und am 20. Juni 1866 als Sohn des Rheders und Kaufmanns J. P. D. Dieseldorff und seiner Ehefrau Maria geb. Rethey zu Hamburg geboren.

Jleinen ersten Unterricht grenoss ich auf dem Johanneum meiner Vaterstadt, dann am Gymnasium zu Ratzeburg, wo ich 1882 in die Obersekunda versetzt wurde.

Gemäss den Bestimmungen meines Vaters habe ich darauf meine kaufmännische Lehrzeit in London begonnen, genügte von 1883-1884 meiner Dienstpflicht und war darauf bis zum Jahre $1891 \mathrm{im}$ väterlichen Geschäfte zu Hamburg und bei meinen Brüdem in Central-Amerika thätig. Im letztgenannten Jahre siedelte ich nach Johannesburg in der Südafrikanischen Republik über, wo ich mich bald ganz dem Berg- und Hüttenwesen widmete, Ietzteres von Grund auf erlernte und zuletzt Stellunæren als Hütten- und Grubenwardein inne hatte. Im Jahre 1895 kehrte jch nach Deutschland zurück und besuchte 1896 in bergbaulicher und finanzieller 'Thätigkeit Australien und Nen-Seeland. Von dort zurückgekommen bezog ich 1897-1898 die kgrl. sächsische Bergakademie zu Freiberg und darauf 1898-1899 die Universität Freiburg in Baden auf je 2 Semester. In Marburg war ich weitere 4 Semester immatrikuliert, wo ich auch am 3. Juli 1901 das Examen rigorosum bestand.

Ileine Herren Lehrer waren:

In Freiberg i. Sachsen: Beck, Kolbeck, Treptow, Uhlich, Weisbach, Winkler.

In Freiburg i. Baden: Autenvieth, G. Böhm, Himstedt, Graeff, Kilian, Neumann, Steinmann, Weissmann.

In Marburg: M. Bauer, v. Below, Cohen, v. Drach, Kayser, Kohl, v. d. Ropp, Schenck, Schröder, Zincke.

Allen ihnen, besonders den Herren Bauer, Beck, Kayser; Steinmann und Zincke sage ich meinen aufrichtigen Dank für die mir erteilte wissen, schaftliche Ausbildung. 


\section{Tafel No. 1.}

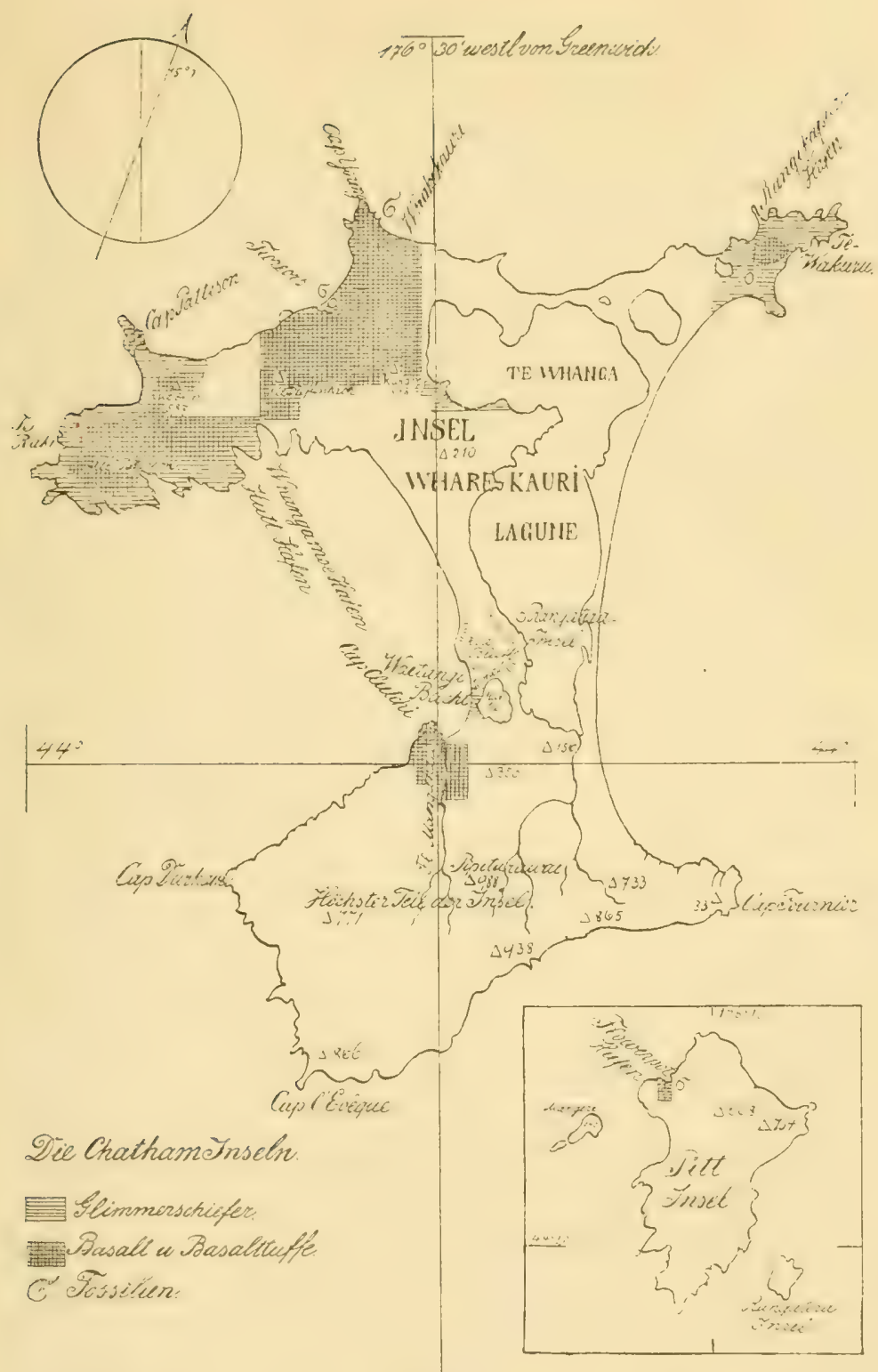

\section{Karte der Chatham Inseln.}

$$
\text { 1: } 560000 \text {. }
$$





\section{Tafel No. 2.}

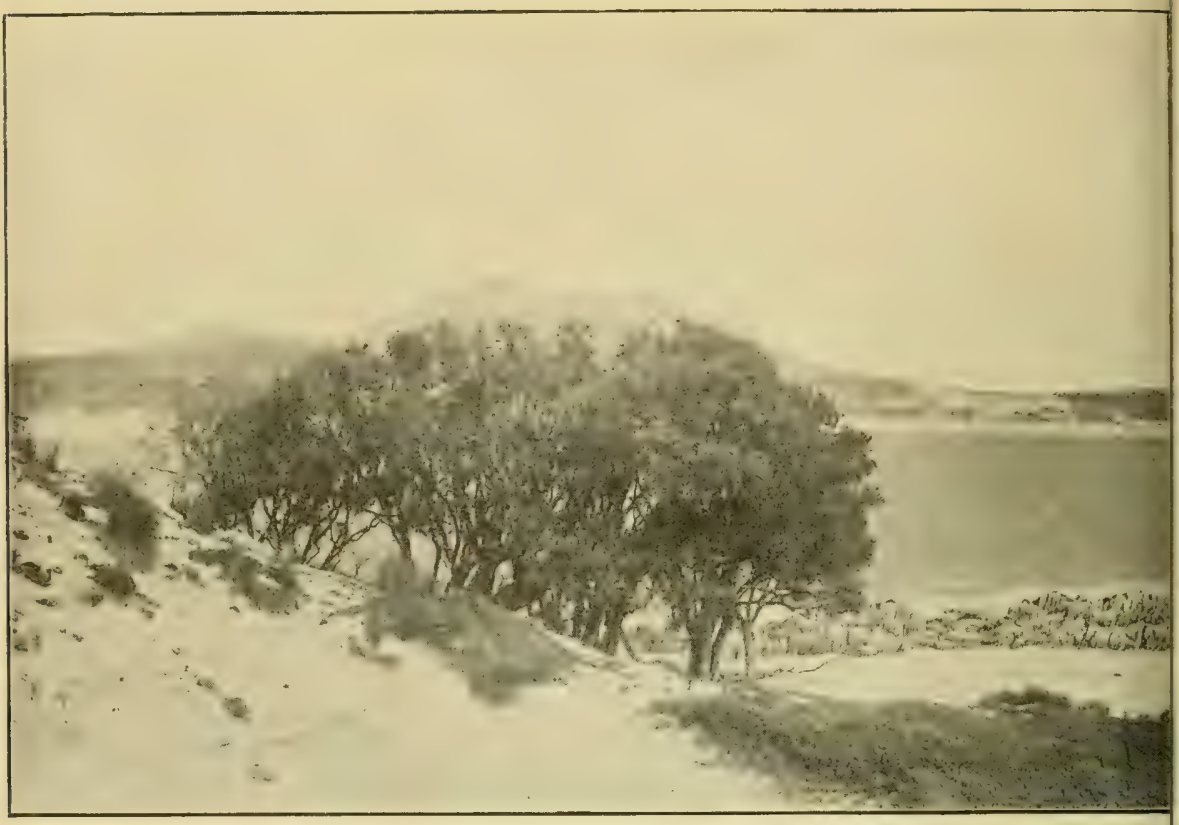

No. 1. (s. S. 8 u. 10 des Textes.)

Ansicht des unweit des Ostcap's gelegenen Kaingaroa Harbour auf den Chatham Inseln.

Links in Vordergrund eine durch Dünen (a) teilweise verschüttete Baumgruppe; rechts vorn an Ufer treten steilgestellte Sericitschiefer (b) auf. Im Hintergrund sieht man den Mt. Korako emporragen.

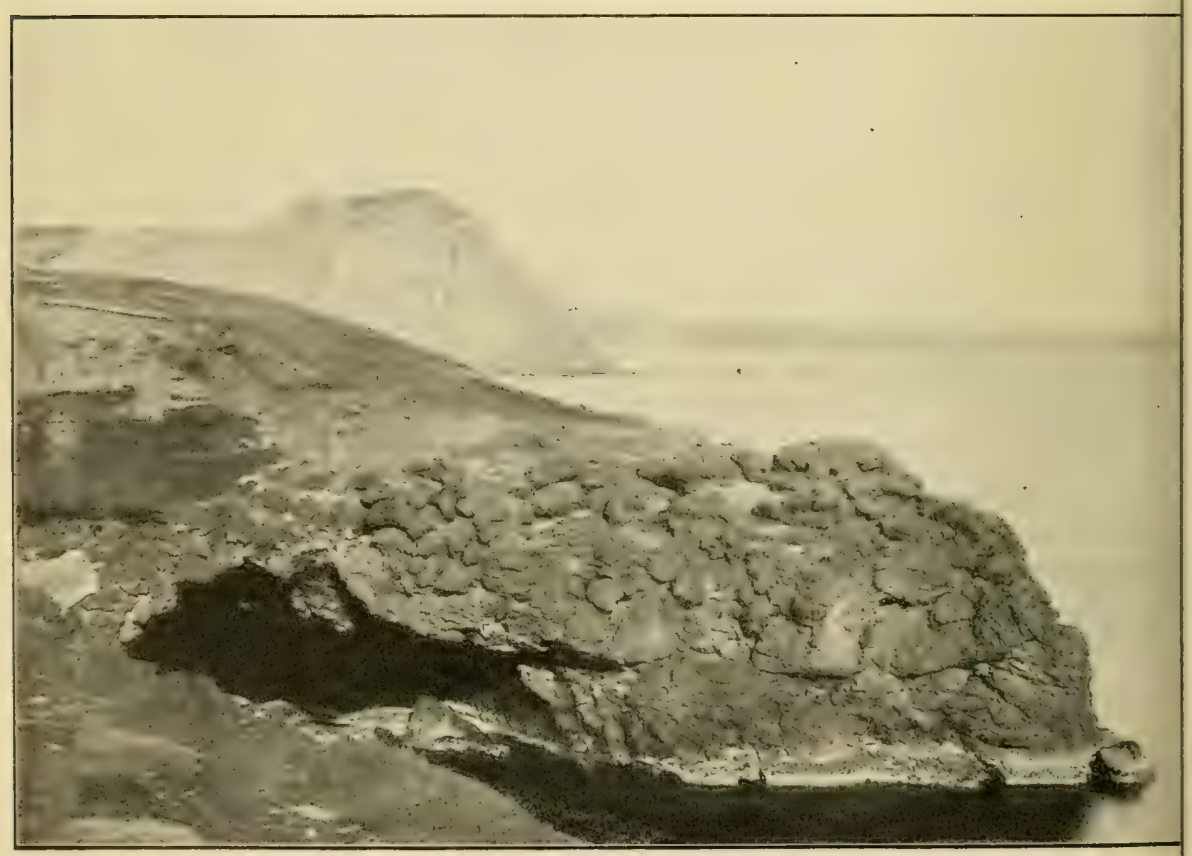

No. 2. (s. S. 17 u. folg. d. Textes.)

Ansicht des Cape Young am Nordufer der Hauptinsel der Chatham Inseln.

Ueber einem fladenartigen basaltischen Lavastrom sieht man den etwas Schichtung zeigenden Tuff= mantel (a); links vorn eine Höhle, in welche das Meer eingetreten ist. 


\section{Tafe1 No. 3.}

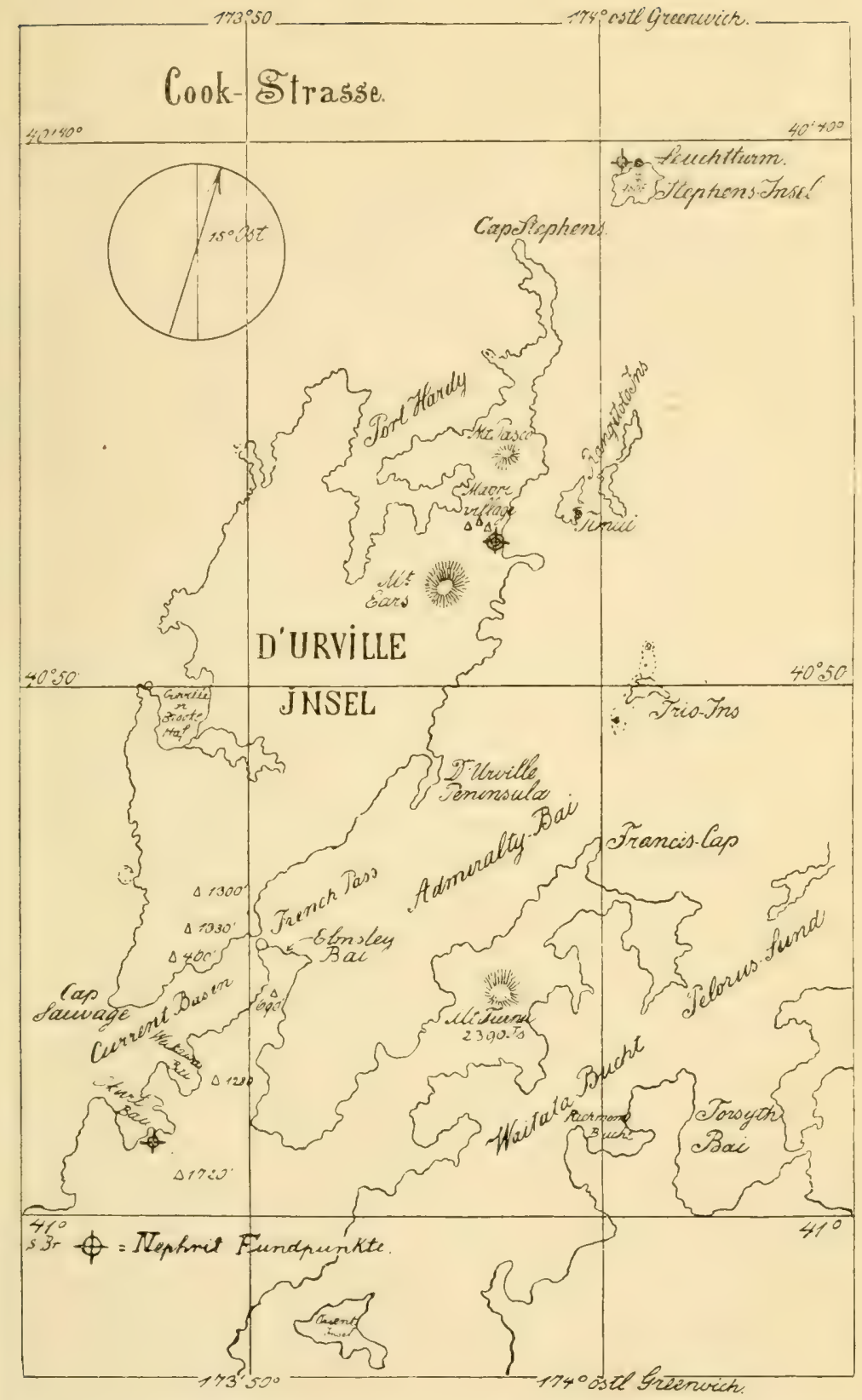

\section{Karte der D'Urville- und der Stephens-Insel}

und ihrer Umgebung. 1:500000. 




\section{Tafel No. 4.}

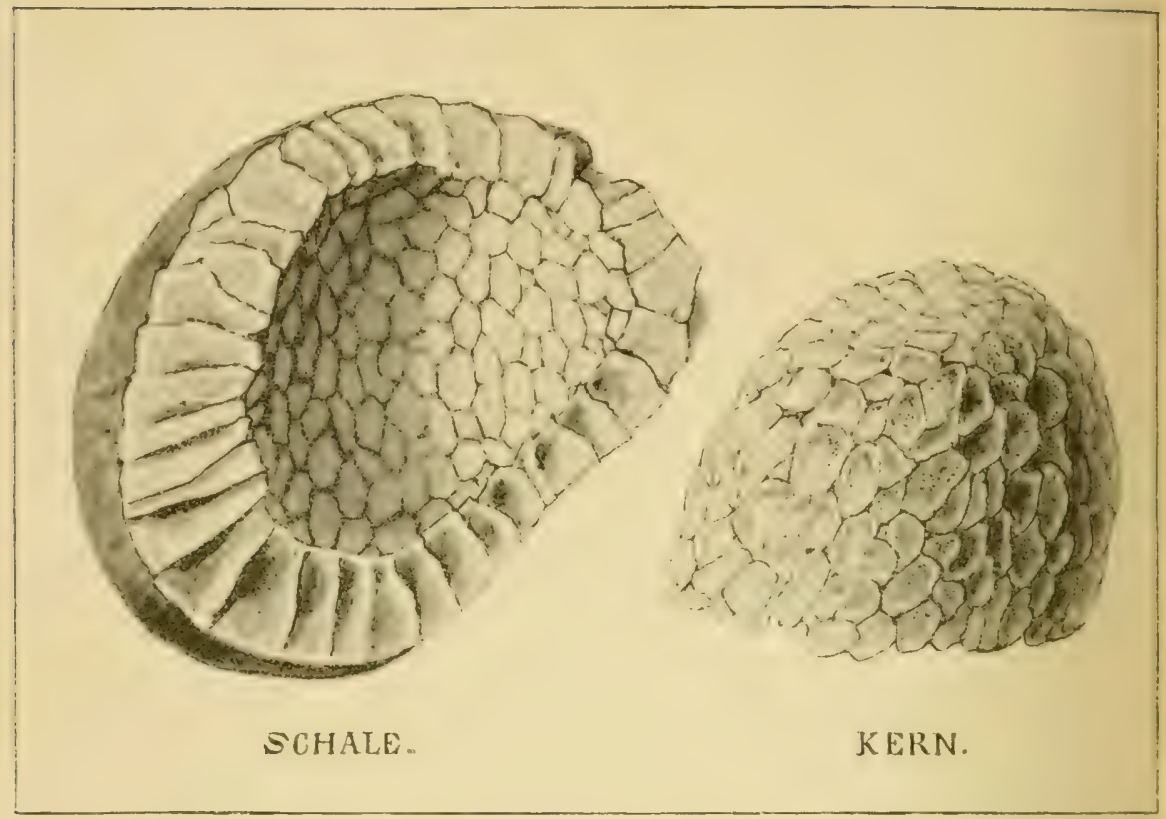

No. 1. Abbildung der auf pag. 36 beschriebenen Ausbildungsweise der Schalsteine, Nrs S. 1f, 16-21, von de Stephens Insel.
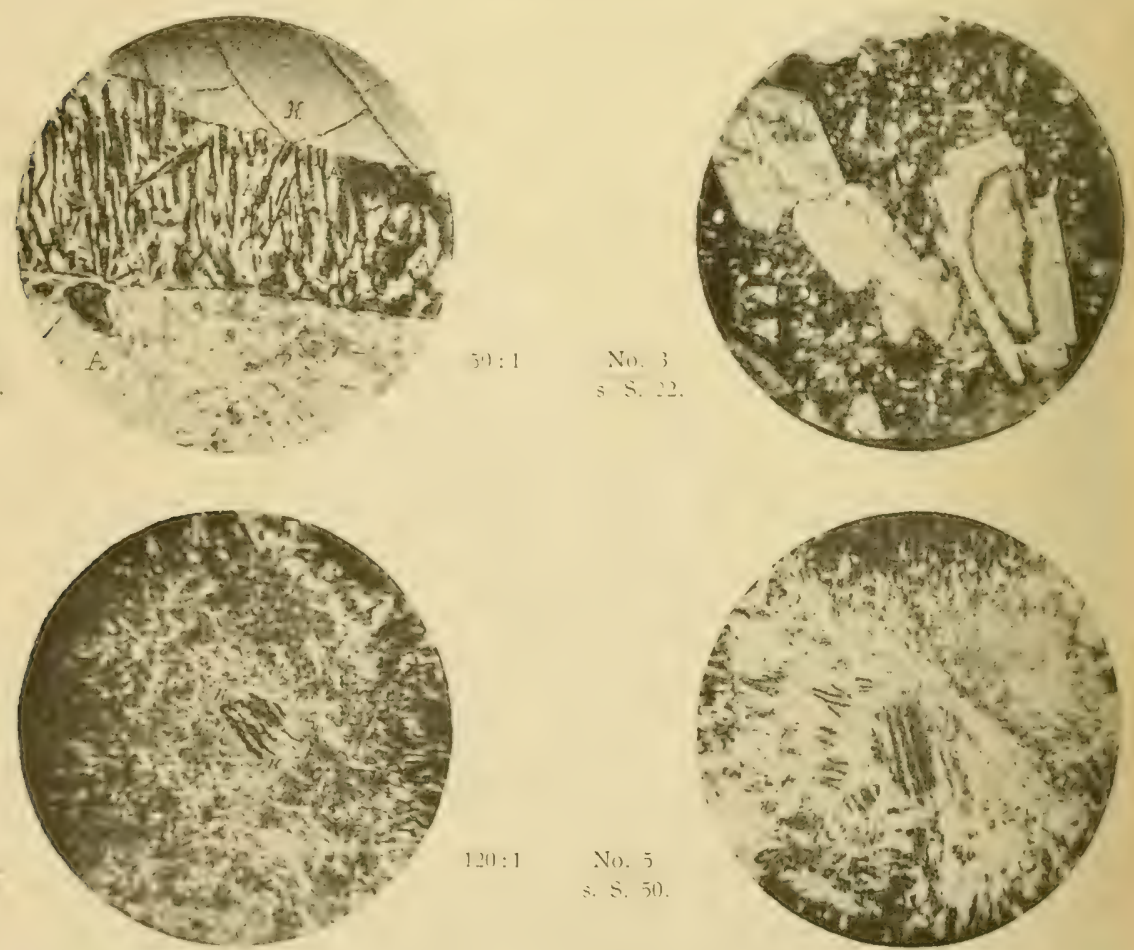

$H=$ Hornblende. $\mathrm{A}=$ Augit. Die Erklärung dieser 4 Mikrophotographien findet sich im Text und zwar auf der durch den Hinweis (S. S. - ) bezeichneten Seite. 



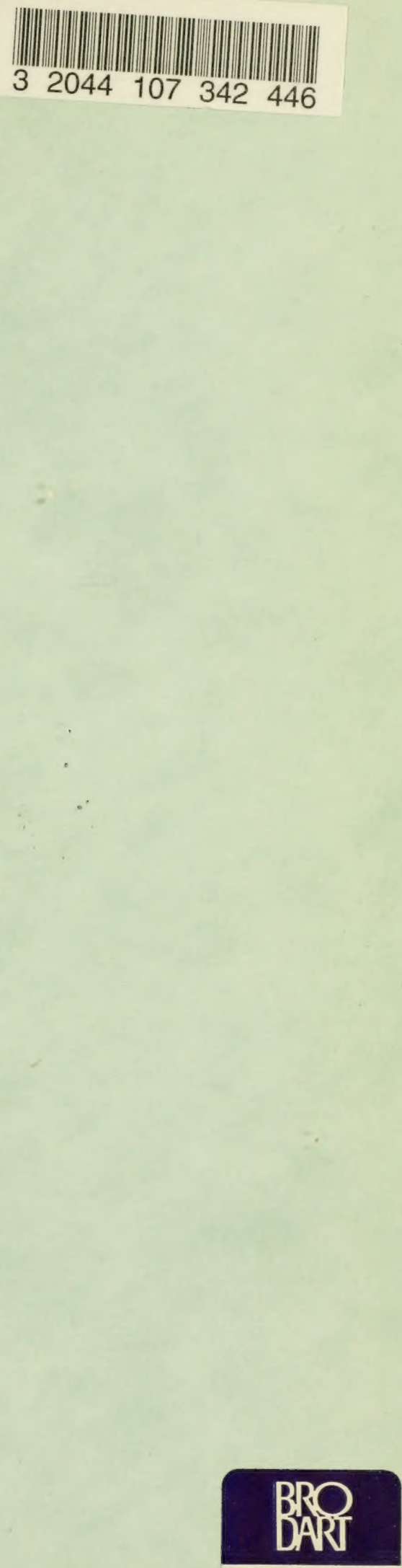

MADE IN U.S,A. 


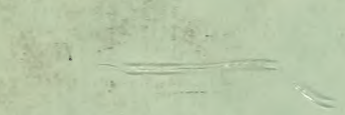

